\title{
I. EXECUTIVE SUMMARY
}

In the previous period of work, twelve overlay hardfacing alloys were selected for erosion testing based upon a literature review. All twelve coatings were deposited on 1018 steel substrates using the plasma arc welding process [1]. Ten samples from each coating were prepared for erosion testing. The coating deposition and sample preparation procedures were described in the previous quarterly report [2]. During the past quarter, all the coatings were erosion tested at $400^{\circ} \mathrm{C}$. The erosion resistance of each coating was evaluated by determining the steady state erosion rate. In addition, the microstructure of each coating was characterized before and after the erosion tests.

This progress report describes the erosion test results and coating microstructures. Also, a preliminary analysis on the relationships between weld overlay coating hardness, microstructure, and erosion resistance will be discussed.

\section{INTRODUCTION}

The erosion of materials by the impact of solid particles has received increasing attention during the past twenty years. Recently, research has been initiated with the event of advanced coal conversion processes in which erosion plays an important role. The resulting damage, termed Solid Particle Erosion (SPE), is of concern primarily because of the significantly increased operating costs which result in material failures. Reduced power plant efficiency due to solid particle erosion of boiler tubes and waterwalls has led to various 
methods to combat SPE. One method is to apply coatings to the components subjected to erosive environments. Protective weld overlay coatings are particularly advantageous in terms of coating quality. The weld overlay coatings are essentially immune to spallation due to a strong metallurgical bond with the substrate material. By using powder mixtures, multiple alloys can be mixed in weld overlay coating systems in order to achieve the best performance in an erosive environment. However, review of the literature revealed a lack of information on weld overlay coating performance in erosive environments [1].

The objective of this project is to determine the effects of weld overlay coating composition and microstructure on erosion resistance. These results will lead to a better understanding of erosion mitigation in coal fired reactor vessels such as CFB's.

\section{EXPERIMENTAL PROCEDURE}

\section{III.1 Coating Deposition}

A fully automatic welding laboratory was used for depositing hardfacing weld overlay coatings [1]. A total of 12 plasma arc weld overlay coatings were deposited on 1018 steel substrates. The plasma Transferred Arc (PTA) process was employed. Nominal chemical compositions of the 11 deposited coatings are listed in Table 1. The Delcrome-92 weld overlay coating initially selected [1] was not used for future evaluation due to poor quality of the deposit. This coating contained a large amount of cracks. Therefore, only 11 weld overlay coatings have been used for the future investigation. The coating deposition procedure was described in the previous quarterly report [2]. 


\section{III.2 Metallographic Analysis}

i. Sectioning and Mounting

After the weld overlay coatings were deposited on the 1018 steel substrates, they were sectioned into 0.5 inch $\times 0.5$ inch coupons for erosion testing. Two uneroded samples from each coating were cross-sectioned and mounted in cold curing, thermosetting epoxy for microstructural analysis. Also, two samples from each coating were cross-sectioned and mounted in the same manner after 100 minutes of exposure in the erosion tester. The sectioning and mounting procedures were described in the previous report $[1,2]$.

\section{ii. Metallography}

The weld overlay coating samples were ground on an automatic polisher to a 600 micron finish using silicon carbide paper. Final polishing was performed to 0.3 micron finish using alumina powder. The coating microstructures were characterized in the as-polished and etched condition using light optical microscopy (LOM). Microstructural observations and photomicrography were conducted with a Zeiss metallograph.

\section{iii. Microhardness Measurements}

Microhardness tests were performed on the transverse sections of all coatings. The room temperature tests started at the surface of the weld and proceeded well into the base metal. The spacing between each indentation was 120 microns. A pyramidal indenter and $1 \mathrm{~kg}$ load were used to obtain the microhardness measurements (Knoop hardness). 


\section{III.3 Erosion Tests}

\section{i. Erosion Tester}

A schematic diagram of the erosion tester that was used in this investigation is shown in Figure 1. The system is driven by an air compressor which can deliver up to $35 \mathrm{scfm}$ of air. The air is cleaned through a series of fibers to remove any entrained water. The flow meter and pressure regulator control the amount of air that flow through the system. The air is heated by two inline fluid heaters to temperatures up to $700^{\circ} \mathrm{C}$ exiting the heaters. Erodent is fed into the air stream with a screw feeder to ensure constant feed rates. The particles and hot air are accelerated and impinge upon the sample at the angle chosen by operator. Particle velocity is measured with a laser Doppler Velosometer (LDV). The sample is always centered under the particle stream.

\section{ii. Erosion Test Conditions}

The standard test conditions that were chosen for this study are:

Coating Sample Size $=0.5$ inch $\times 0.5$ inch

Sample Temperature $=400^{\circ} \mathrm{C}$

Erodent Particles Velocity $=40 \mathrm{~m} / \mathrm{s}$

Erodent Particles Flux $=8.56 \mathrm{mg} /\left(\mathrm{mm}^{2} / \mathrm{sec}\right)$

Impingement Angle $=90^{\circ}$ and $30^{\circ}$

Erodent $=$ alumina $\left(\mathrm{Al}_{2} \mathrm{O}_{3}\right)$

Erodent size $=300$ microns 
Exposure time $=5,10,20,50$, and $100 \mathrm{~min}$

The sample size was chosen to be 0.5 inch $\times 0.5$ inch because these dimensions are slightly smaller than the acceleration tube inner diameter $(0.6$ inch). Therefore, the top surface of the coatings are completely covered by the erodent particle stream and provide a uniform erosion scar. An example of a typical erosion sample is shown in Figure 2.

The sample temperature was chosen to be $400^{\circ} \mathrm{C}$, similar to the temperature of the fireside boiler tube surface in the lower part [3]. The particle velocity and flux rate values are similar to those used by other researchers in this area $[4,5]$. The erodent particle velocity is reported as an average velocity. The standard deviation was found $+o$ be approximately $10 \%$.

The particle impingement angles were chosen to be $90^{\circ}$ and $30^{\circ}$. The impingement angle is defined as the angle between the direction of the impinging particles and the metal surface at the point of impact [6]. From the literature review, it was found that some ductile materials exhibited a maximum erosion rate at $20-30^{\circ}$ impact angles [6] while several brittle materials exhibited maximum rates at a $90^{\circ}$ impact angle. Based upon these results it was decided to conduct erosion tests at these two impingement angles in order to evaluate potential variations in erosion rates between classes of overlays (i.e. ductile vs. brittle) due to differences in impact angle.

For many materials it was found that erosion rate is independent of erodent particle size for particles larger than about 100 to $200 \mathrm{um}$ in diameter [6,7]. Therefore, erodent particle size was chosen to be $300 \mathrm{um}$. 


\section{iii. Steady State Erosion Rate Determination}

The erosion kinetics which are typical of most materials are schematically shown in Figure 3 . The weight loss of a given material as a function of time during erosion often follows a pattern consisting of a relatively small incubation period with little or no material removal. Apparently, incubation periods are indicative of the time required for sufficient work hardening prior to localized fracture. The material eventualiy experiences surface weight loss and surface hardening at the same rates, and attains a steady state erosion rate. Steady state erosion is defined by the linear portion of the weight loss versus erosion time graph [6]. Determination of the steady state erosion rate is very important from a practical point of view since most of the material removal occurs during this period. Five different erosion exposure times $(5,10,20,50$, and $100 \mathrm{~min}$.) were used in this study in order to adequately obtain the weight loss vs. erosion time plot for each weld overlay coating. For some coatings, an additional $80 \mathrm{~min}$ test was conducted. One sample was used per each erosion time. Therefore, five or six samples from each coating were used in order to obtain the relationship between weight loss and erosion exposure time for each impingement angle. To quantify weight loss during the erosion experiments, the erosion coupons were ultrasonically cleaned in acetone and weighed before the erosion tests to the nearest $0.1 \mathrm{mg}$. The samples were handled with plastic tweezers to avoid contamination and stored in wax paper envelopes until testing. Once the erosion tests were complete, the samples were again ultrasonically cleaned in acetone and weighed to determine the weight change due to erosion. The graphs of weight loss vs. time of exposure were obtained for each weld overlay coating for each impingement angle. A computer program was used in order to determine the best 
linear fit of the data points to obtain the steady state erosion rate.

\section{RESULTS}

\section{IV.1 Microstructural Characterization}

The mictrostructures of the all weld overlay coatings are shown in Figures 4-14. Inspection of the photomicrographs shows that most of the coatings (Stellite-6, Ultimet, Inconel-625, Hastelloy-22, B-60, High Chromium Cast Iron, 316L SS, and 420 SS) exhibit dendritic microstructures that are typical for weld materials. The microstructures of all the coatings are very inhomogeneous due to segregations and variations in cooling rates at different regions of the weld. Particular features of each coating class are noted below.

\section{COBALT-BASE COATINGS}

Figure 4-6 shows photomicrographs of the cobalt-base weld overlay coatings. Other work has shown that, for Stellite-6 weld overlay coatings (Figure 4), the primary dendrites (white phase) are a cobalt-rich face-centered structure while the interdendritic eutectic regions (mixed dark and white phase) contain hard $M_{7} C_{3}$ carbides $[9,10,11]$. It has been indicated that these eutectic hard phases in the Stellite-6 significantly contribute to abrasion resistance [10].

The microstructures of TS- 2 and Ultimet weld overlay coating are shown in Figure 5 and 6 , respectively. The coating microstructures consist of second phase particles (dark features) and metal matrix (white regions). The second phase particles may be carbides and/or intermetalics. Future works is required to determine quantitative and qualitative information about the phases in the TS-2 and Ultimet weld overlay coatings. 


\section{NICKEL-BASE COATINGS}

Figures 7-9 show microstructures of the nickel-base weld overlay coatings. It was observed that the dendrites in Inconel-625 coating (Figure 8) are smaller than those in Hastelloy-22 coating (Figure 7). Welding and solidification behavior of Inconel-625 alloy has been studied by many authors [12]. It was found that the interdendritic regions consisted of $\mathrm{NbC}$ type carbides and Laves phases. The Laves phase can be of the form $\mathrm{Ni}_{3} \mathrm{SiNb}_{2}$ [13]. It also has been established that the weld microstructure of the Inconel-625 alloy is controled by segregations of the niobium, carbon, and silicon [12]. Apparently, the matrix of the Inconel625 consists of the $\mathrm{Y}$ phase. The effect of these microstructural features on erosion resistance needs to be determined.

From Figure 9a it can be seen that the microstructure of the B-60 weld overlay coating consists of a crack that runs at a $45^{\circ}$ angle to the coating surface. It was found that microstructure in the vicinity of the crack is the same as a microstructure away from the crack. Therefore, the microstructure of the coating did not play a role in the crack formation. The mechanism of the crack formation was described in the previous quarterly report [2].

\section{IRON-BASE COATINGS}

The photomicrographs of the iron-base weld overlay coatings are shown in Figures 10-14. The Iron-Aluminide coating microstructure is significantly different from all other coatings studied. This microstructure is shown in Figure $10(a, b, c, d)$. From Figures 10a and 10b (low magnification) the grain morphology of the coating can be seen. The coating microstructure 
consists of equiaxed grains at the coating/base metal interface and at the top of the weld. Large columnar grains are present between equiaxed grains regions. Also, second phase precipitates within the grains (dark features) can be observed from photomicrographs. High magnification photomicrographs of these precipitates within the grain and at the grain boundaries are shown in Figures 10c and 10d. The chemical compositions of these precipitates was not determined.

The microstructure of the Armacor-M weld overlay coating is shown in Figure 11 (a,b,c,d and e). From Figures $11 \mathrm{a}$ and $11 \mathrm{~b}$ it can be seen that the coating microstructure possesses a needle-like phase of various sizes (white phase) in a metal $(\mathrm{Cr}-\mathrm{Fe})$ matrix. Based upon its microstructural appearance and chemical composition of the alloy powder, it is expected that this needle-like phase is a boride. Figure 11c and 11d show high magnification views of the needle-like phase that has a broad size distribution. Also, cracks were observed in Armacor-M weld overlay deposit. Again, the mechanism of the crack formation is discussed in previous quarterly report [2]. The photomicrograph of the coating microstructure that consists of the crack is shown in Figure 11e. The observed cracks were perpendicular to the weld bead and run from the top of the coating to the coating/substrate interface.

The photomicrographs of the High-Chromium Iron is shown in Figure $12(a, b, c)$. The Microstructure of as-cast high-chromium irons have been investigated by many authors [14]. It was found that the as-cast microstructure consisted of austenite dendrites with an interdendritic mixture of austenite and $\mathrm{Cr}$-rich $\mathrm{M}_{7} \mathrm{C}_{3}$ carbides [14].

The microstructure of the 316L SS (austenitic stainless steel) and 420 SS (martensitic stainless steel) weld overlay coatings are shown in Figures 14 and 15, respectively. The 
microstructure of the 316L SS coating possesses dendrites of delta ferrite (dark phase) and an austenite matrix (white phase). The microstructure of the 420 SS coating contains dendrites of lath martensite (Figure 14b) and interdendritic regions may contain ferrite or/and austenite (white phase). Inspection of the Figure 14c (high magnification) shows the prior austenite grains in the coating microstructure.

\section{IV.2 EROSION TESTS}

The erosion test conditions were described in section III.3. The erosion tests results are summarized in Table 2.

\section{IV.2.1. Cobalt-Base Weld Overlay Coatings}

The erosion kinetics of the cobalt-base coatings at $90^{\circ}$ and $30^{\circ}$ impact angles are shown in Figures 15 and 16, respectively. Also shown on the graphs are the slopes of the best-fit straight lines through the data points. The slopes of these lines give the steady state erosion rate in milligrams per minute $(\mathrm{mg} / \mathrm{min})$. At $90^{\circ}$ impact angle, the Ultimet and TS- 2 coatings have nearly identical erosion rates, $0.072 \mathrm{mg} / \mathrm{min}$ and $0.074 \mathrm{mg} / \mathrm{min}$, respectively. The TS-2 coating exhibits an incubation time of an approximately $5 \mathrm{~min}$. The Stellite- 6 weld overlay coating has a higher steady state erosion rate- $0.101 \mathrm{mg} / \mathrm{min}$. This coating has a relatively long incubation time of an approximately $20 \mathrm{~min}$. Also, the Stellite- 6 weld overlay coating shows the highest steady state erosion rate $(0.104 \mathrm{mg} / \mathrm{min})$ at $30^{\circ}$ impact angle. As with the $90^{\circ}$ impact angle, the Ultimet and TS- 2 coatings have similar steady state erosion rates at $30^{\circ}(0.082$ and $0.091 \mathrm{mg} / \mathrm{min}$, respectively). No inc abation periods were found for any of the coatings at the $30^{\circ}$ impact angle. It can be seen that the steady state erosion rates for the 
Stellite- 6 and Ultimet weld overlay coatings do not vary significantly with impingement angle.

\section{IV.2.2. Nickel-Base Weld Overlay Coatings}

The erosion kinetics for the nickel-base coatings at $90^{\circ}$ and $30^{\circ}$ are shown in Figure 17 and 18, respectively. From Figure 17 it can be seen that Inconel-625 exhibited the smallest erosion rate $(0.081 \mathrm{mg} / \mathrm{min})$ and the B-60 coating has the highest erosion rate $0.110(\mathrm{mg} / \mathrm{min})$. Also, the Inconel-625 weld overlay coating showed an incubation time of approximately 20 min. It was found that at $30^{\circ}$ impact angle (Figure 18) all the nickel-base weld overlay coatings showed similar steady state erosion rates (about $0.081 \mathrm{mg} / \mathrm{min}$ ). Also, for the Inconel- 625 coating, the steady state erosion rates does not vary with the impingement angle and an incubation period was not detected. The small incubation time $(5 \mathrm{~min})$ was documented for B-60 weld overlay coating.

\section{IV.2.3. Iron-Base Weld Overlay Coatings}

The erosion kinetics for the iron-base weld overlay coatings at $90^{\circ}$ and $30^{\circ}$ impact angles are shown in Figures $10-22$. The Armacor-M coating showed the highest erosion rate $(0.162$ $\mathrm{mg} / \mathrm{min}$ ) at $90^{\circ}$ impact. Also, 316L SS, 420SS, Iron-Aluminide, and High Chromium Iron showed similar steady state erosion rates $(0.078,0.073,0.073$, and $0.084 \mathrm{mg} / \mathrm{min}$,

respectively). In addition, the Armacor-M, Iron-Aluminide, and 316L SS coatings showed an incubation time of approximately $20 \mathrm{~min}$. The $420 \mathrm{SS}$ coatings showed the highest steady state erosion rates $\left(0.148\right.$ and $0.111 \mathrm{mg} / \mathrm{min}$, respectively) at $30^{\circ} \mathrm{impact}$ angle (Figure 21 and 22, respectively). The 316L SS and Iron-Aluminide weld overlay coatings exhibited lowest 
steady state erosion rates $(0.072$ and $0.066 \mathrm{mg} / \mathrm{min})$ at $30^{\circ} \mathrm{impact}$ angle. High Chromium Iron weld overlay coating exhibited a moderate steady state erosion rate $(0.086 \mathrm{mg} / \mathrm{min})$ at $30^{\circ}$. However, the steady state erosion rate for High Chromium Iron coating is similar to the erosion rates for Ultimet (cobalt-base) and Inconel-625 (nickel-base) coatings.

\section{IV.3. Microhardness Tests}

Microhardness tests were performed on transverse sections of all the weld overlay coatings. The room temperature microhardness tests results are shown in Figures 23-34. It can be seen that all the coatings have a higher hardness than the substrate material (1018 steel). The scatter is a resu'" of the non-homogeneous microstructures, which include large amounts of second phase particles that vary in size and composition. The average room temperature hardness of each coating is plotted against the steady state erosion rate were for $30^{\circ}$ and $90^{\circ}$ particle impact angles. The results are shown in Figures 35 and 36 . No significant correlations between room temperature hardness and steady state erosion rates were found. However, it is interesting to note that Armacor-M and B-60 weld overlay coatings had the highest hardness and exhibited the highest erosion rates at $90^{\circ}$ erodent particles impact angle.

\section{DISCUSSION}

Based upon the results of the erosion tests it was established that some weld overlay coatings such as Ultimet, TS-2, Inconel-625, Iron-Aluminide, 316L SS, and High Chromium Iron exhibited steady state erosion rates which are similar and significantly lower than the 
erosion rates for remaining coatings. This result is rather surprising considering that these coatings have different base-materials (cobalt, nickel, and iron), chemical compositions, and microstructures. It was also established that room temperature hardness did not correlate to erosion resistance (Figure 35 and 36). Previous work on weld overlay coatings has shown that increases in coating hardness lead to an increase in their abrasion resistance [18]. However, other authors showed that hardness did not affect erosion resistance [17]. The results obtained in the present investigation suggest that an increase in the hardness of the coatings do not necessarily represent an increase in their erosion resistance. Moreover, weld overlay coatings that have a relatively low hardness level (below $350 \mathrm{HK}$ ) such as Inconel625, Iron-Aluminide and 316L SS consistently show a higher erosion resistance whereas some of the coatings with higher hardness show lower erosion resistance (Armacor-M and B-60. Therefore, room temperature hardness measurements are not a valid criteria for the selection of erosion resistant weld overlay coatings. Usually, materials with lower hardness possess a higher toughness and work hardening coefficient than materials with higher hardn js. It was indicated in the literature [19] that the critical mechanical properties which control erosion resistance include fracture strength, toughness, and work hardening. Therefore, the coatings that showed similar erosion rates at elevated temperature may have similar toughness and work hardening rates at this temperature. It is probable that each coating type attains these similarities in mechanical properties by different mechanisms. For example, in IronAluminide coatings, the presence of the antiphase boundaries may affect its mechanical properties. The design of the test that will determine mechanical properties of the coatings that might be responsible for their erosion resistance is in progress. Identification of the laboratory test which can be used as an indicator of the erosion resistance will permit the 
relationship between mechanical properties, microstructure, and erosion resistance to be established. Such information will be valuable for selecting erosion resistant weld overlays in CFB's.

It was observed that for Stellite-6, Ultimet, Inconel-625, Iron-Aluminide, Armacor-M, High Chromium Iron, and 316L SS coatings the steady state erosion rates did not vary significantly with the erodent particles impingement angles (Table 2). Previous work $[6,20]$ has suggested that erosion of ductile materials is greatest when the angle of impact is in $20^{\circ}$ to $30^{\circ}$ degree range [20], whereas the erosion of brittle materials is greatest at $90^{\circ}$ degrees [6]. However, the present investigation showed that these observations may not be valid for weld overlay coatings. Kosel et.al [14] and Ninham [17], showed that for a series of iron, cobalt, nickel base wrought alloys and weld deposits, their erosion rates did not vary considerably with the impact angle variations. More work is required to determine the effect of impingement angle on the erosion resistance of weld overlay coatings.

Lastly,the results of the present investigation were compared with the those obtained by Stein on the erosion resistance of the various thermal spray coatings [21]. Stein used the same experimental conditions that were employed in this research. It was found that the weld overlay coatings exhibited a much higher erosion resistance (generally by factor of $1.5-2$ ) than thermal spray coatings. The thermal spray coatings often contain high levels of porosity and oxides (1-30\%) within the coating which promote coating failure in erosive environments $[5,21]$. In contrast, weld overlays coatings contain no porosity or oxides within the coatings and, as a result, offer better erosion protection than thermal spray coatings. 


\section{CONCLUSIONS}

Based upon erosion testing and microstructural characterization of the 11 weld overlay coatings the following can be concluded:

1. The steady state erosion rates at elevated temperature $\left(400^{\circ} \mathrm{C}\right)$ were found to be similar for the Ultimet, TS-2, Inconel-625, Iron-Aluminide, 316L SS, and High Chromium Iron. These coatings had different base materials. Their steady state erosion rates were considerably lower than the rest of the investigated weld overlay coatings.

2. No correlations were found between room temperature microhardness of the weld overlay coatings and their erosion resistance at elevated temperature $\left(400^{\circ} \mathrm{C}\right)$. Therefore, selection of the erosion resistant weld overlay coatings for boiler tubes in CFB's should not be based on their room temperature microhardness values.

4. The Stellite-6, Ultimet, Inconel-625, Iron-Aluminide, Armacor-M, High Chromium Iron, and 316L SS weld overlay coatings did not show significant differences in their steady state erosion rates for $30^{\circ}$ and $90^{\circ}$ erodent particles impact angles at elevated temperature $\left(400^{\circ} \mathrm{C}\right)$. 


\section{FUTURE WORK}

Mechanical tests will be performed in order to evaluate the effect of work-hardening, fracture strength, and toughness of the weld overlay coatings on their erosion resistance. Relationships between mechanical properties of the weld overlay coatings and their erosion resistance will be determined. Microstructural evaluations of selected coatings will be continued by using Scanning electron microscopy (SEM), energy dispersive spectrometry (EDS), and wavelength- dispersive spectrometry (WDS) in order to identify phases that are present. The objective of this future work is to identify the key microstructural parameters which provide good erosion resistance so that weld overlay coatings can be selected for erosion mitigation in CFB's. 


\section{REFERENCES}

1. Levin, R.F., Dupont, J.N., and Marder, A.R., Quarterly Technical Progress Report For The Period January 1993 through March 1993, Lehigh University, Energy Research Center, 93500-9-15.

2. Levin, B.F., Dupont, J.N., and Marder, A.R., Quarterly Technical Progress Report For The Period April 1993 through June 1993, Lehigh University, Energy Research Center, 93-500-1527.

3. Lewnard, J., Air Products and Chemicals, Private Communication.

4. Levy, A.V., Yan, J., and Patterson, J., Wear, vol 111, pp.1-13, December, 1985.

5. Bluni, S.T. and Smith, B.J., Life Extension Of Power Plant Boiler Tubes By Protective Coatings, Final Report, Lehigh University, Energy Research Center, 92-500-1-2, January, 1992.

6. Hatchings, I.M., Monograph On The Erosion Of Materials By Solid Particle Impact, MTI Publication No 10, 1983.

7. Hatchings, I.M., Corrosion/Erosion Of Coal Conversion Systems (Proc. Conf.), pp. 393428, january, 1979.

8. Metals Handbook, Ninth Edition, Vol. 11, Failure Analyis and Prevention, ASM, p.155, 1986.

9. Silence, W.L., Effect Of Structure On Wear Resistance Of Co-, Fe-, and Ni-base,

10. Berns, H., Fischer, A., and Theisen, W., Development Of New Co-base Hardfacing Alloys, Wear Of Materials, Vol 2, p. 601-610, 1989.

11. ASM Handbook, Friction, Lubrication, and Wear Technology, Vol. 18, pp 758-765, 1992.

12. Cieslak, M.J., The Welding and Solidification Metallurgy Of Alloy 625, Welding Research Supplement, pp. 49-56, February 1991.

13. Bardos, D.I., Gupta, K.P., and Beck, P.A, Transactions TMS-AIME, Vol 221, p. 1087, 1961.

14. Aptecar, S.S. and Kosel, T.H., Erosion Of White Cast Irons and Stellite, Wear of Materials, 1985.

15. Metals Handbook, Desk Edition, ASM, p 15.1, 1991.

16. Haller, M., Metalls Handbook, Vol. 9, Ninth Edition, ASM.

17. Ninham, A., The Effect Of Mechanical Properties On Erosion, Wear Of Materials, Vol.

2, pp. 813-823, 1987.

18. Berns, H., Fisher, A., and Theisen, W., Abrasive Wear Resistance and Microstructure Of $\mathrm{Ni}-\mathrm{Cr}-\mathrm{B}-\mathrm{Si}$ Hardfacing Alloys with additions of $\mathrm{Al}, \mathrm{Nb}, \mathrm{Mo}, \mathrm{Fe}, \mathrm{Mn}$ and $\mathrm{C}$, Wear Of Materials, Vol.2, pp 535-542, 1987.

19. Ball, A., On The Importance Of Work Hardening In The design Of Wear-Resistant Materials, Wear, 91, pp 201-207, 1983.

20. Levy, A.V., Mechanism Of Combined Erosion-Corrosion Of Steel At Elevated Temperatures, Corrosion and Particle Erosion At High Temperatures, V. Srinivasan and K. Vedual, ed., Minerals, Metals and Materials Society, p. 207, 1989.

21. Stein, K., Erosion Behavior Of Selected Coatings, Final Report, Lehigh University, Energy Research Center, 93-50()-16-28, August, 1993. 
Table 1. Nominal Chernical Composition of the Deposited Weld Overiay Coatings.

\section{COBALT-BASE ALLOYS}

1) I STELLITE-6 (62\%Co-28\%Cr-4.5\%W-1.1\%C-1.0\%Si-2.3\%Fe)

2) TRISTELLE-TS2 (37\%Fe-35\%Cr-11\%Co-9\%Ni-4.5\%Si-2\%C)

3) ULTIMET (57\%, Co-24\%Cr-4.8\%Mo-8.8\%Ni-2.9\%Fe-2\%W-0.058\%C)

\section{NICKEL-BASE ALLOYS}

1) HASTELLOY-22 (57.1\%Ni-21\%Cr-13\%Mo-2.95\%W-0.006\%C-5.15\%Fe)

2) INCONEL-625 (61.7\%Ni-21.7\%Cr-8.5\%Mo--3.49\%(Nb+Ta)-0.023\%C)

3) $\mathrm{B}-60(73.8 \% \mathrm{Ni}-13.4 \% \mathrm{Cr}-4.2 \% \mathrm{Si}-4.3 \% \mathrm{Fe}-2.8 \% \mathrm{~B}-0.67 \% \mathrm{C})$

IRON-BASE ALLOYS

1) ARMACOR-M (59\%Cr-39\%Fe-8\%B-3\%Si)

2) IRON-ALUMINIDE (14.3\%Al-2\%Cr-84.7\% Fe)

3) HIGH CHROMIUM WHITE IRON (68.7\%Fe-27\%Cr-0.44\%Mn-0.6\% Si-0.27\%Ni-0.12\%Mo-

$0.11 \% \mathrm{~N}-2.74 \% \mathrm{C})$

4) $316 \mathrm{~L} \mathrm{SS}(69 \% \mathrm{Fe}-16.5 \% \mathrm{Cr}-2.1 \% \mathrm{Mo}-10.2 \% \mathrm{Ni}-1.45 \% \mathrm{Mn}-0.027 \% \mathrm{C}$ )

5) $420 \mathrm{SS}(85.73 \% \mathrm{Fe}-13.07 \% \mathrm{Cr}-0.425 \% \mathrm{Si}-0.35 \% \mathrm{Mn}-0.4 \% \mathrm{C})$ 
Table 2. Steady State Erosion Rates For Tested Weld Overlay Coatings.

\begin{tabular}{|c|c|c|}
\hline \multirow[t]{2}{*}{ COATING } & \multicolumn{2}{|c|}{ EROSION RATE $(\mathrm{mg} / \mathrm{min})$} \\
\hline & $90^{\circ}$ impact angle & $30^{\circ}$ impact angle \\
\hline COBALT-BASE & & \\
\hline STELLITE- 6 & 0.101 & 0.104 \\
\hline ULTIMET & 0.072 & 0.082 \\
\hline TS-2 & 0.076 & 0.091 \\
\hline NICKEL-BASE & & \\
\hline INCONEL 625 & 0.080 & 0.081 \\
\hline HASTELLOY-22 & 0.099 & 0.082 \\
\hline$B-60$ & 0.110 & 0.081 \\
\hline$\underline{\text { IRON-BASE }}$ & & \\
\hline IKON ALUMINIDE & 0.074 & 0.066 \\
\hline ARMACOR-M & 0.162 & 0.148 \\
\hline HIGH CHROMIUM IRON & 0.084 & 0.086 \\
\hline 316L SS & 0.078 & 0.072 \\
\hline $420 \mathrm{SS}$ & 0.073 & 0.111 \\
\hline
\end{tabular}




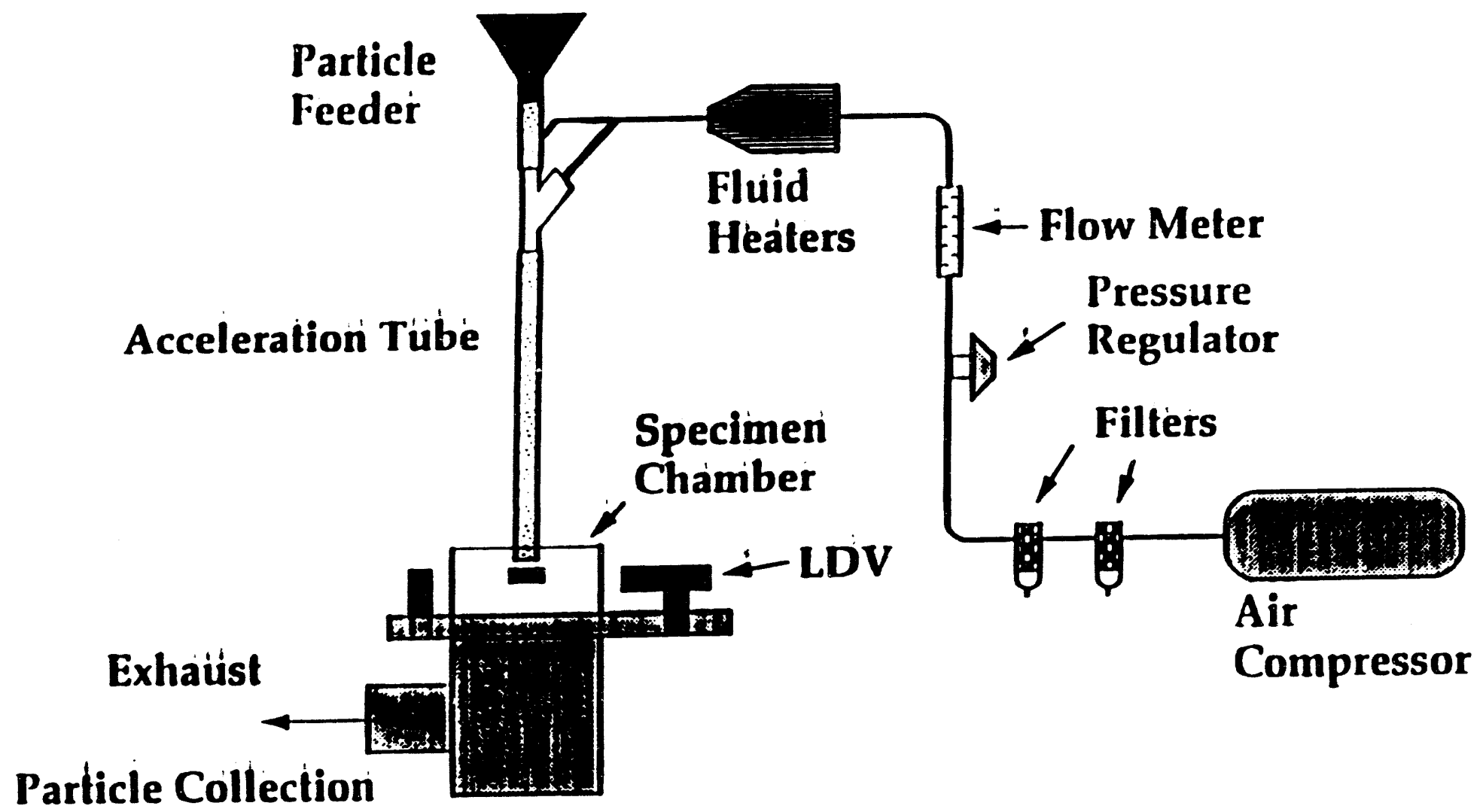

Figure 1. Schematic Diagram of the Erosion Tester. 


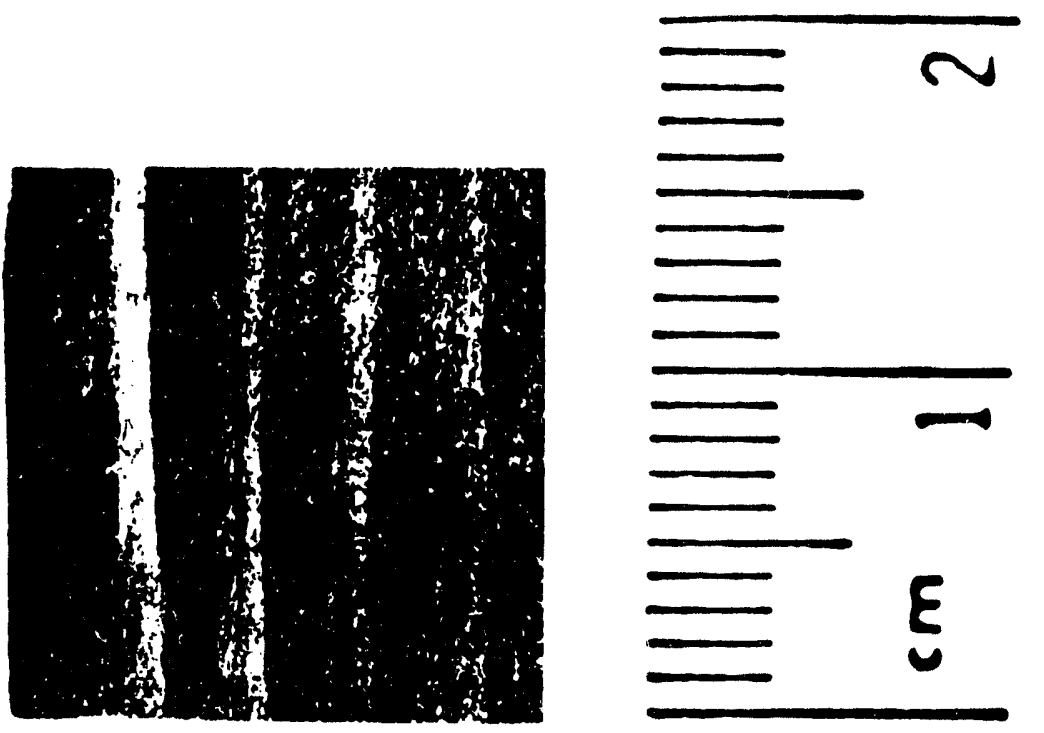

Figure 2. Top view of the typical erosion sample. (Hastelloy-22 weld overlay coating). 


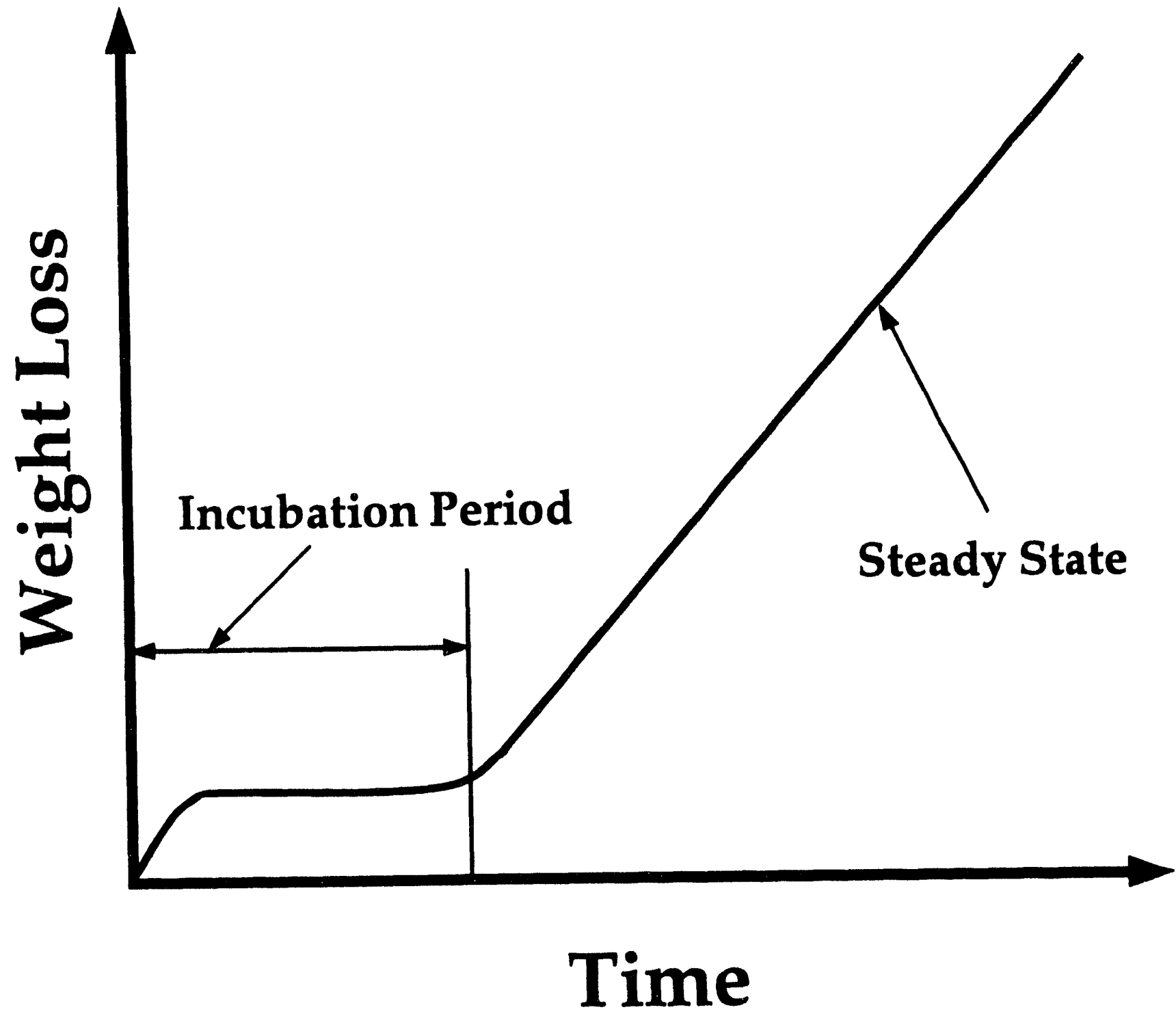

Figure 3. A Schematic Diagram of the Erosion Kinetics. 

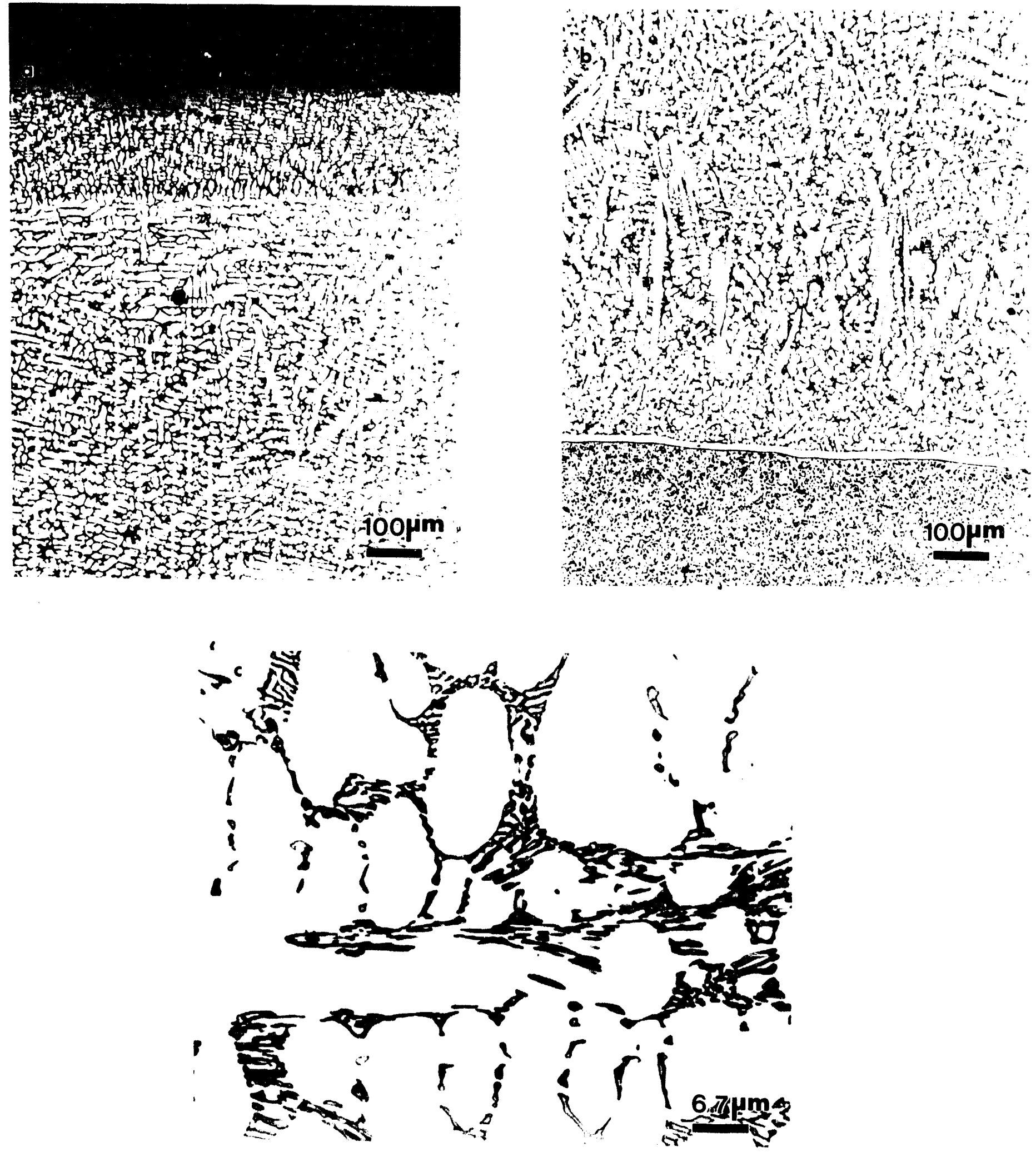

Figure 4. As-Weld Microstructure of the Stellite-6 Weld Overlay Coating; (a) top of the coating; (b) coating/substrate interface, (c) matrix dendrites (white) and interdendritic phase (dark). 

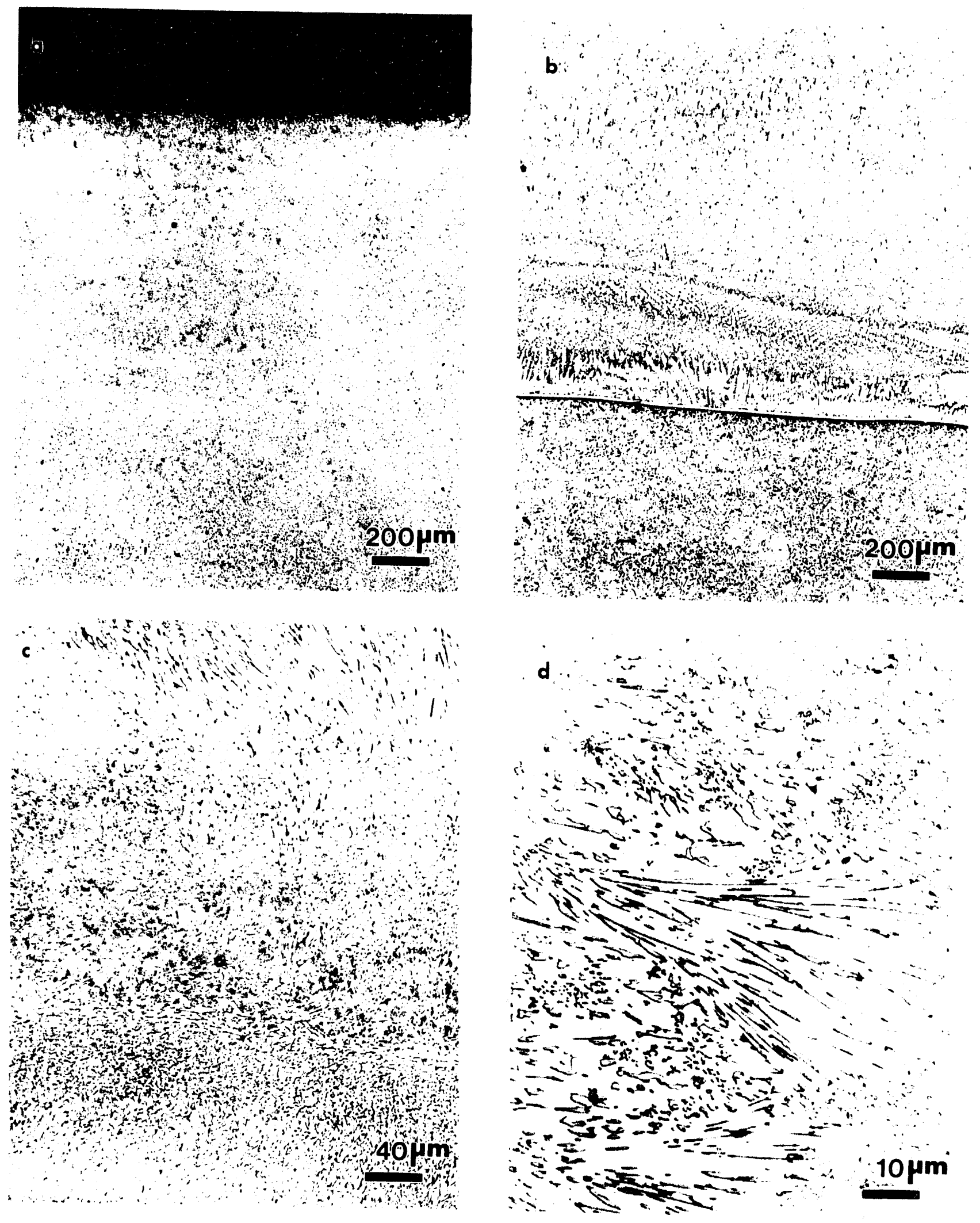

Figure 5. As-Weld Microstructure of the TS-2 Weld Overlay Coating; (a) top of coating; (b) coating/substrate interface; (c,d) second phase particles (dark phase) 

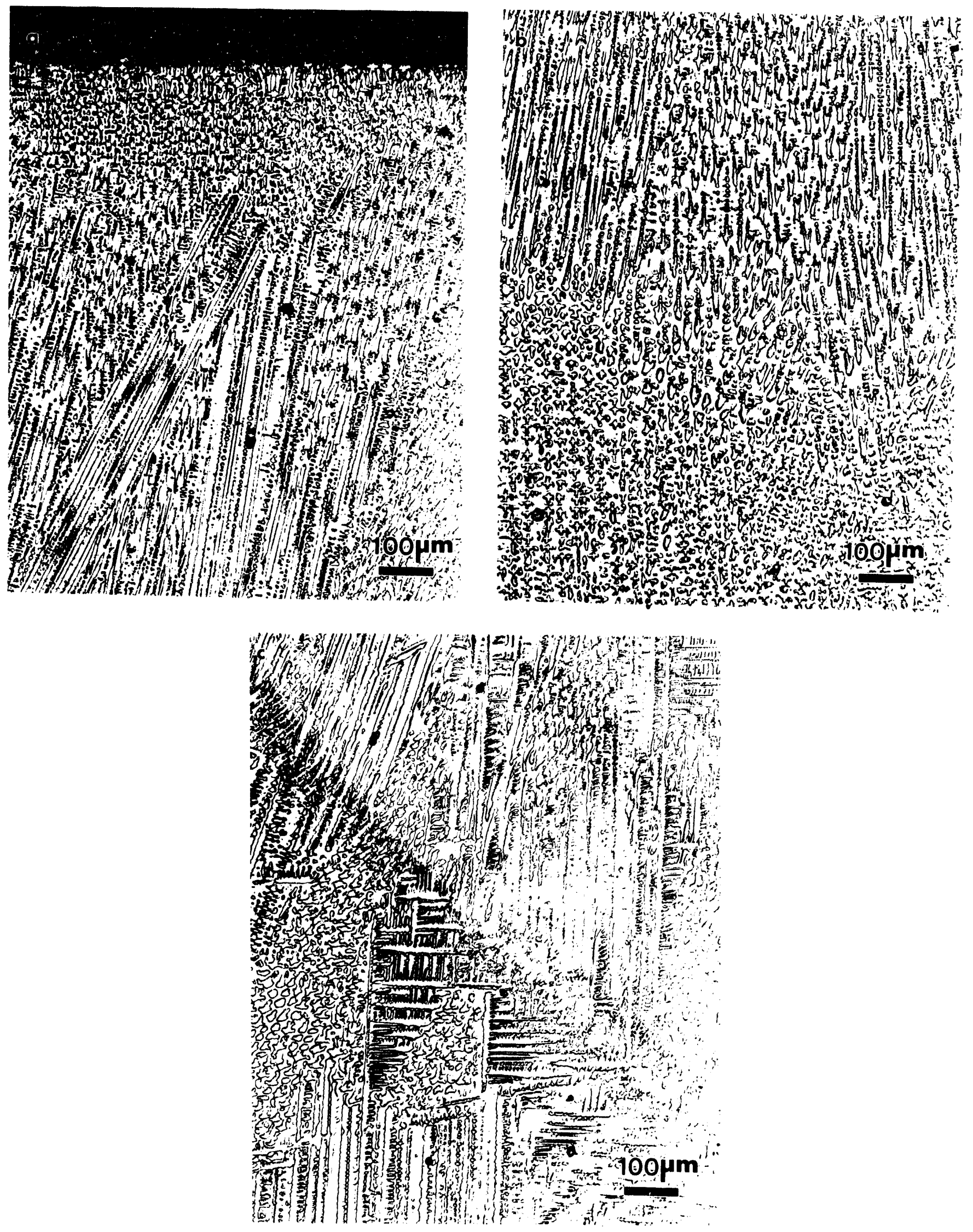

Figüre 6. As-Weld Microstructure of the Ultimet Weld Overlay Coating; (a) top of the coating; (b),(c) dendritic microstructure in different regions of the sample; 


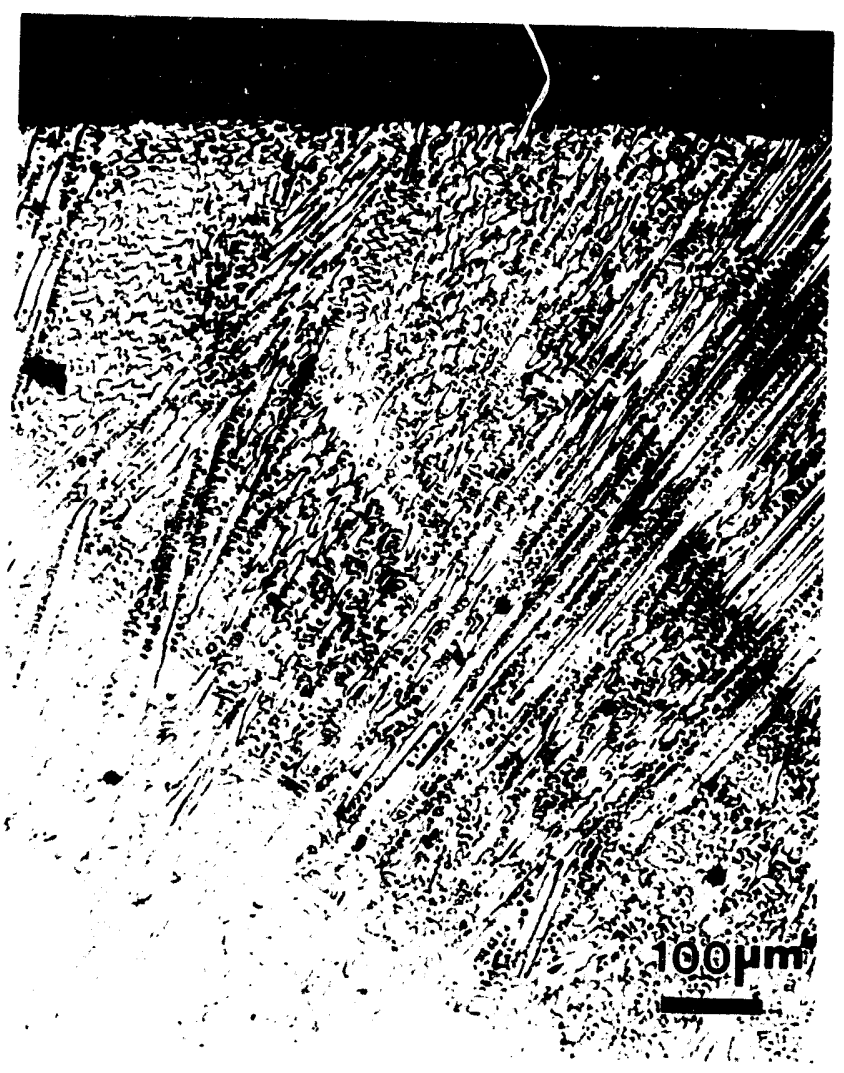

Figure 7. As-Weld Microstructure of the Hastelloy-22 Weld Overlay Coating (top of the coating) 


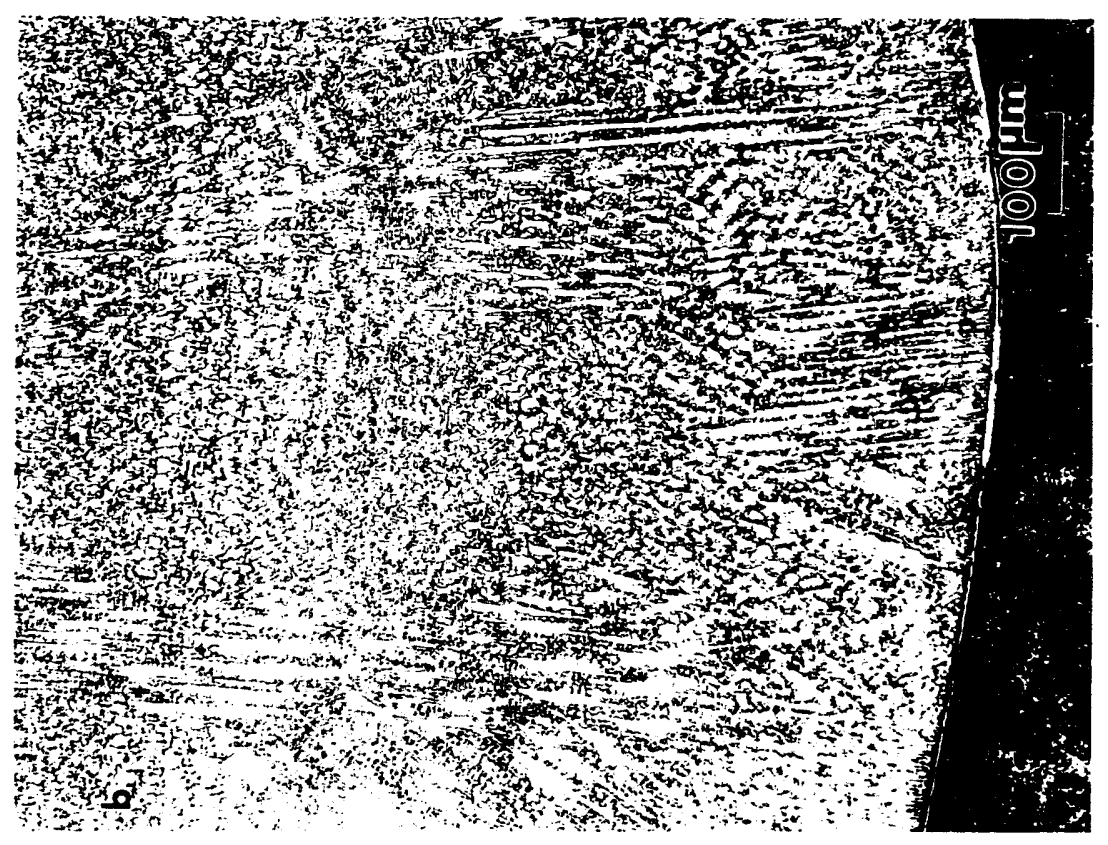

200 a

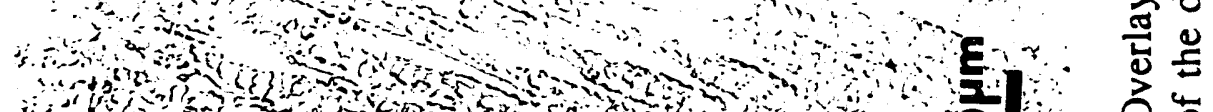
और ming

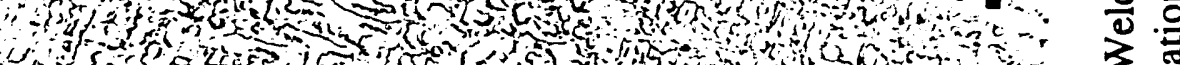

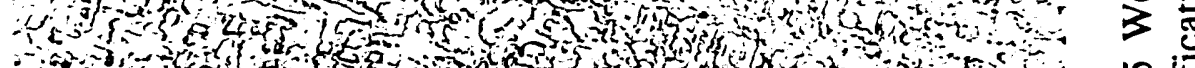
; ret

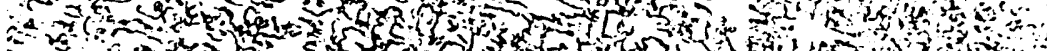

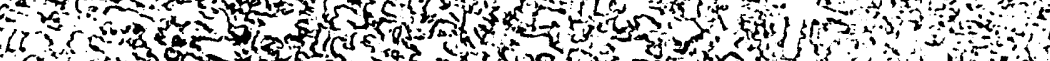
(1)

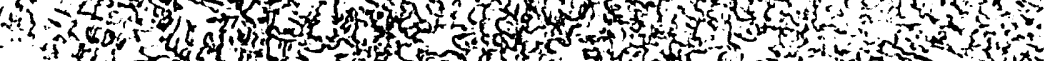

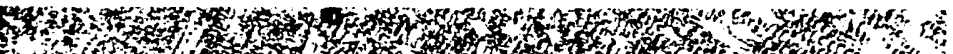

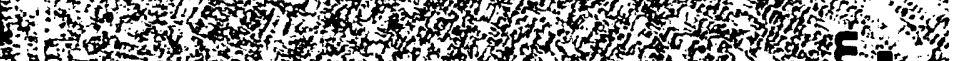

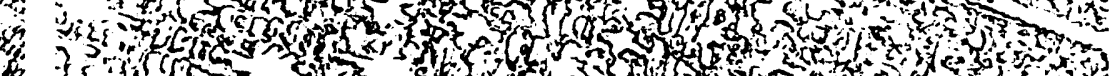

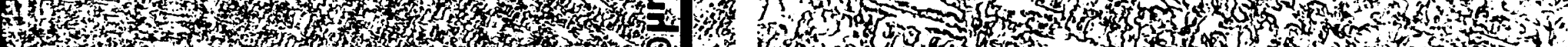

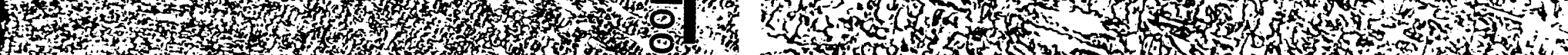

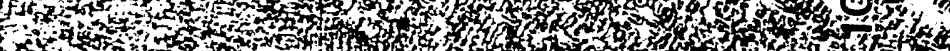
1.20.

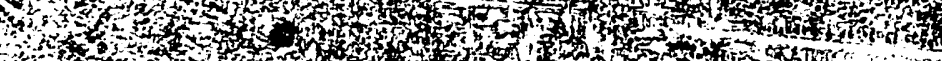

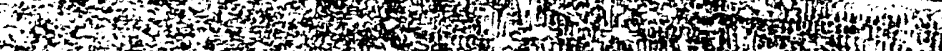

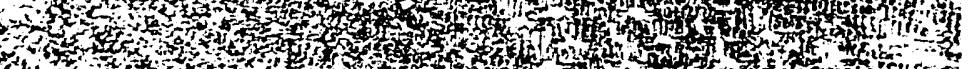

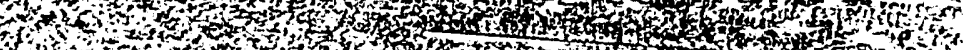

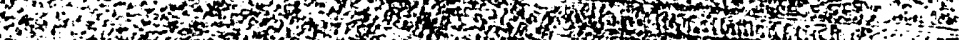
3.2.

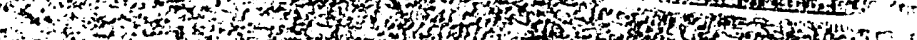

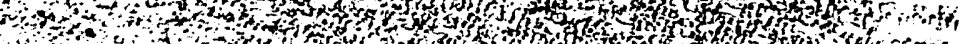

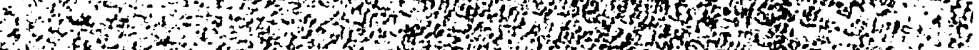

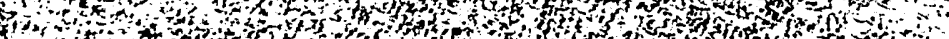

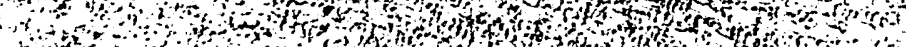

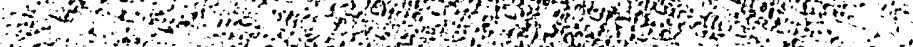

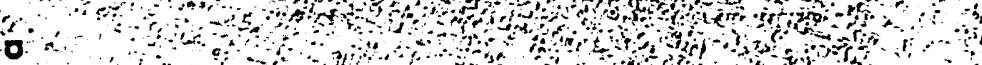

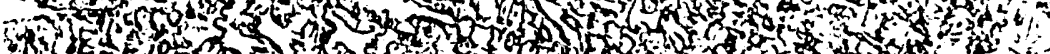

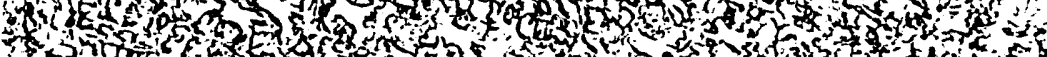

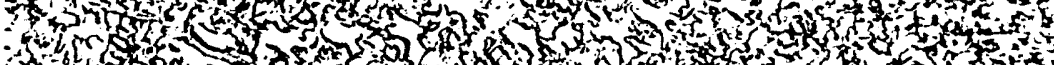

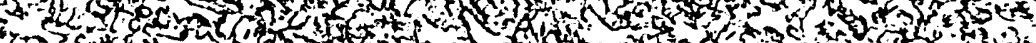
4.

돌

$\stackrel{5}{5}$

范

氖窇

岂.

额

$\sum \frac{1}{3}$

믐

遂

is

五

$\infty$

ㄴ.

证漹 

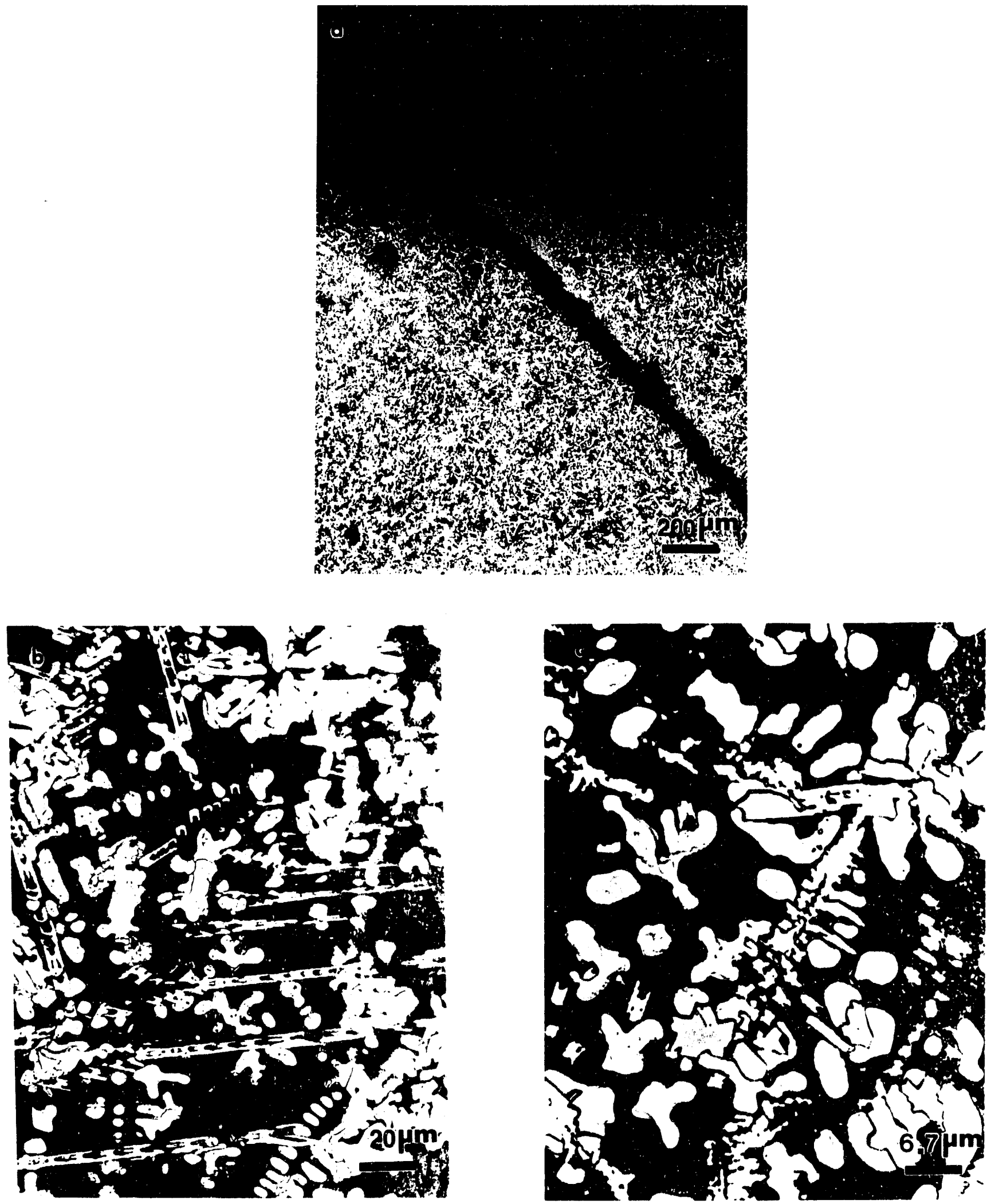

Figure 9. Microstructure of the B-60 Weld Overlay Coating; a) Crack that started from the top of the coating; b),c) high magnifications of the dendritic structure. 

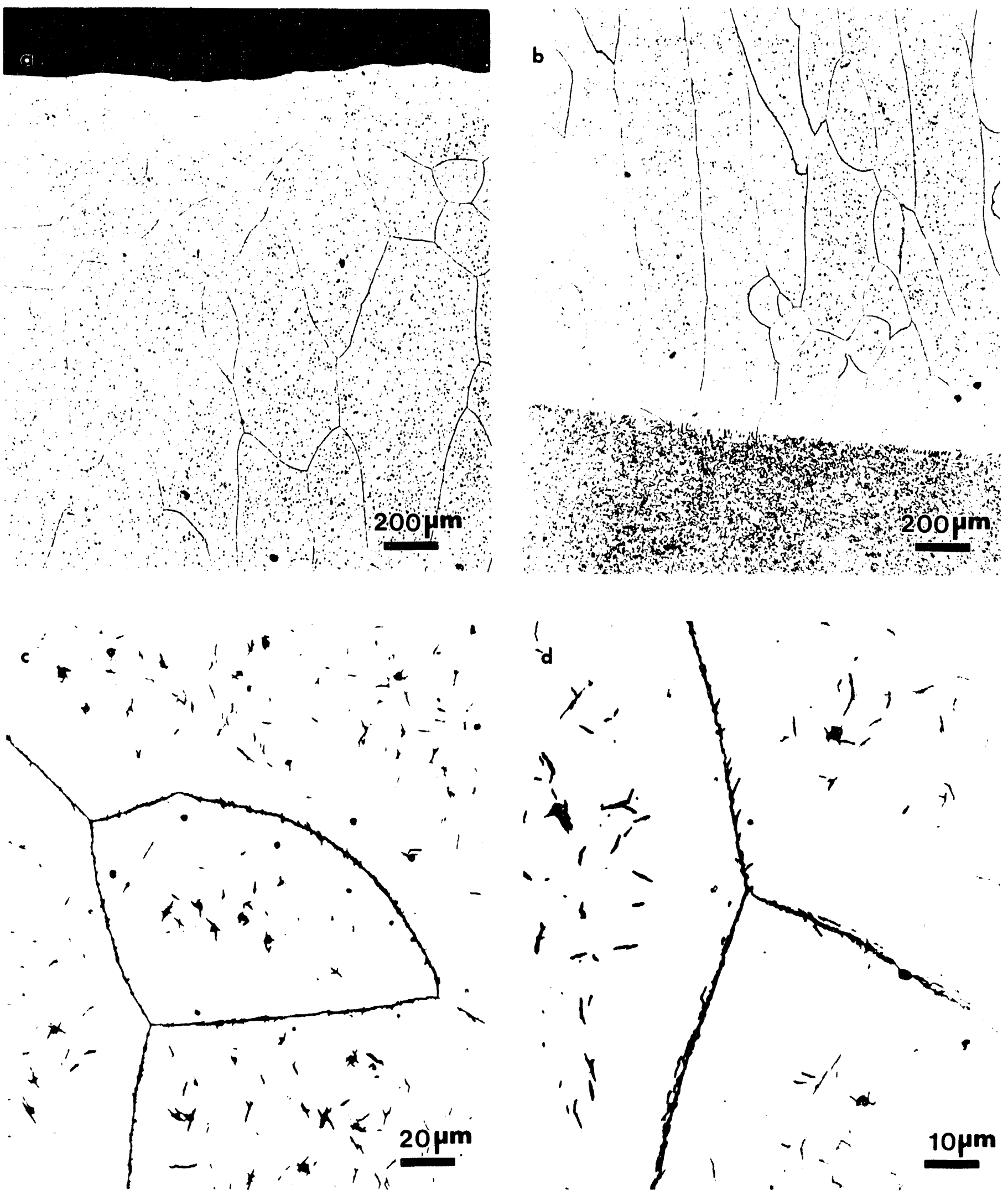

Figure 10. As-Weid Microstructure of the Iron-Aluminide Weld Overlay Coating; (a) top of the coating; (b) coating/substrate interface; (c) precipitates within the grain; (d) precipitates at the grain boundaries. 


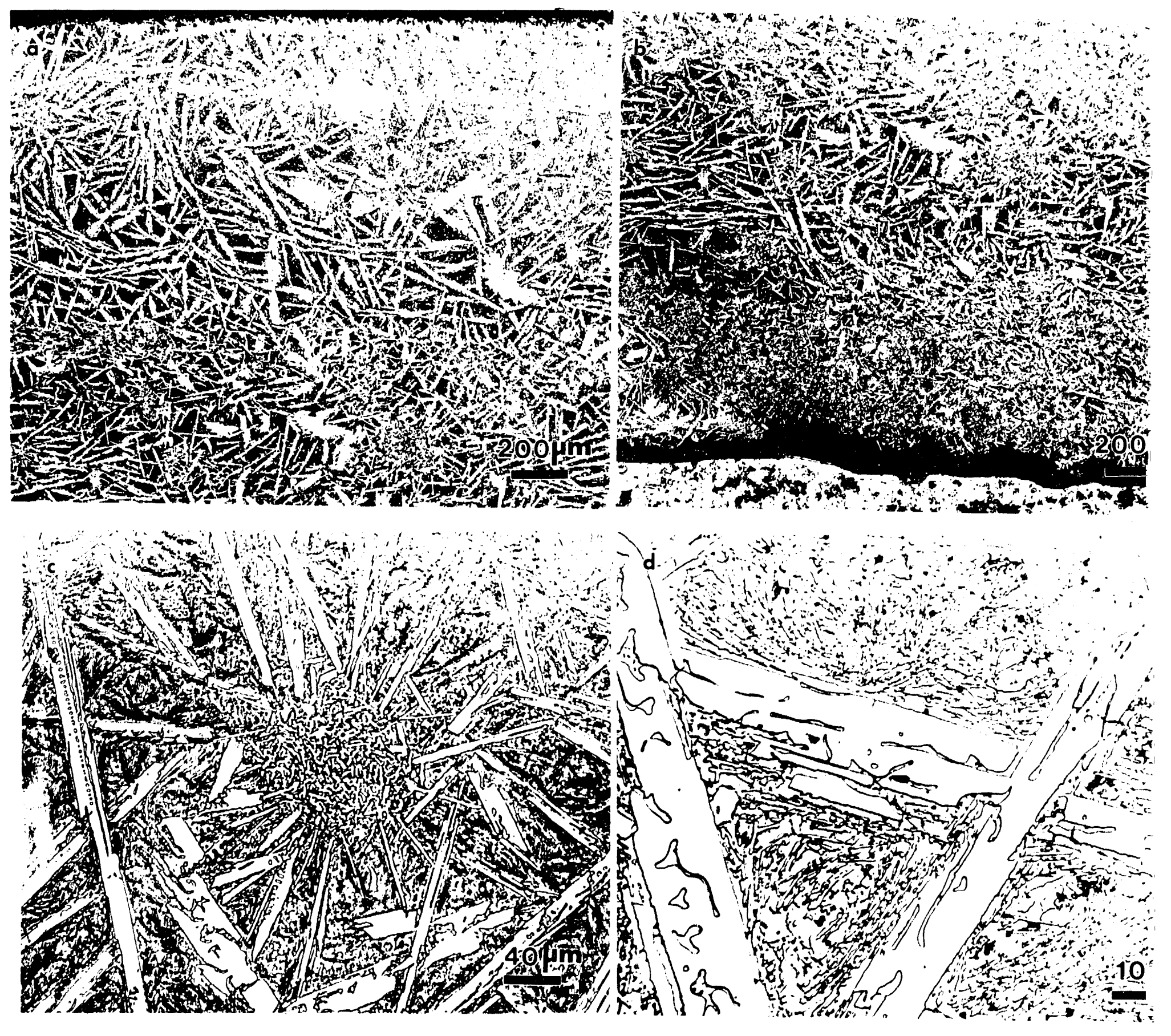

Figure 11. As-Weld Microstructure of the Armacor-M Weld Overlay Coating; (a) top of the coating; (b) coating/substrate interface; (c),(d) high magnification views of the needle-like phase 


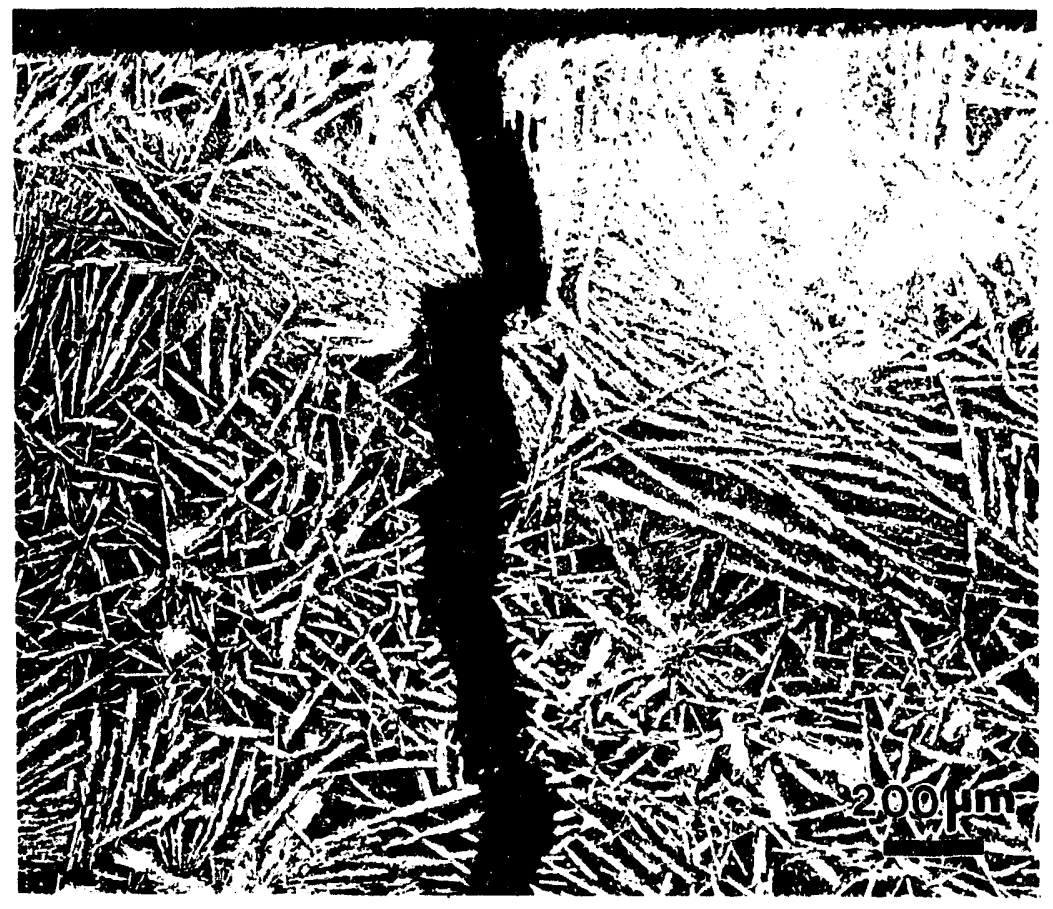

Figure 11e. As-weld Microstructure of the Armacor-M Weld Overlay Coating (crack that run from the top of the coating. 

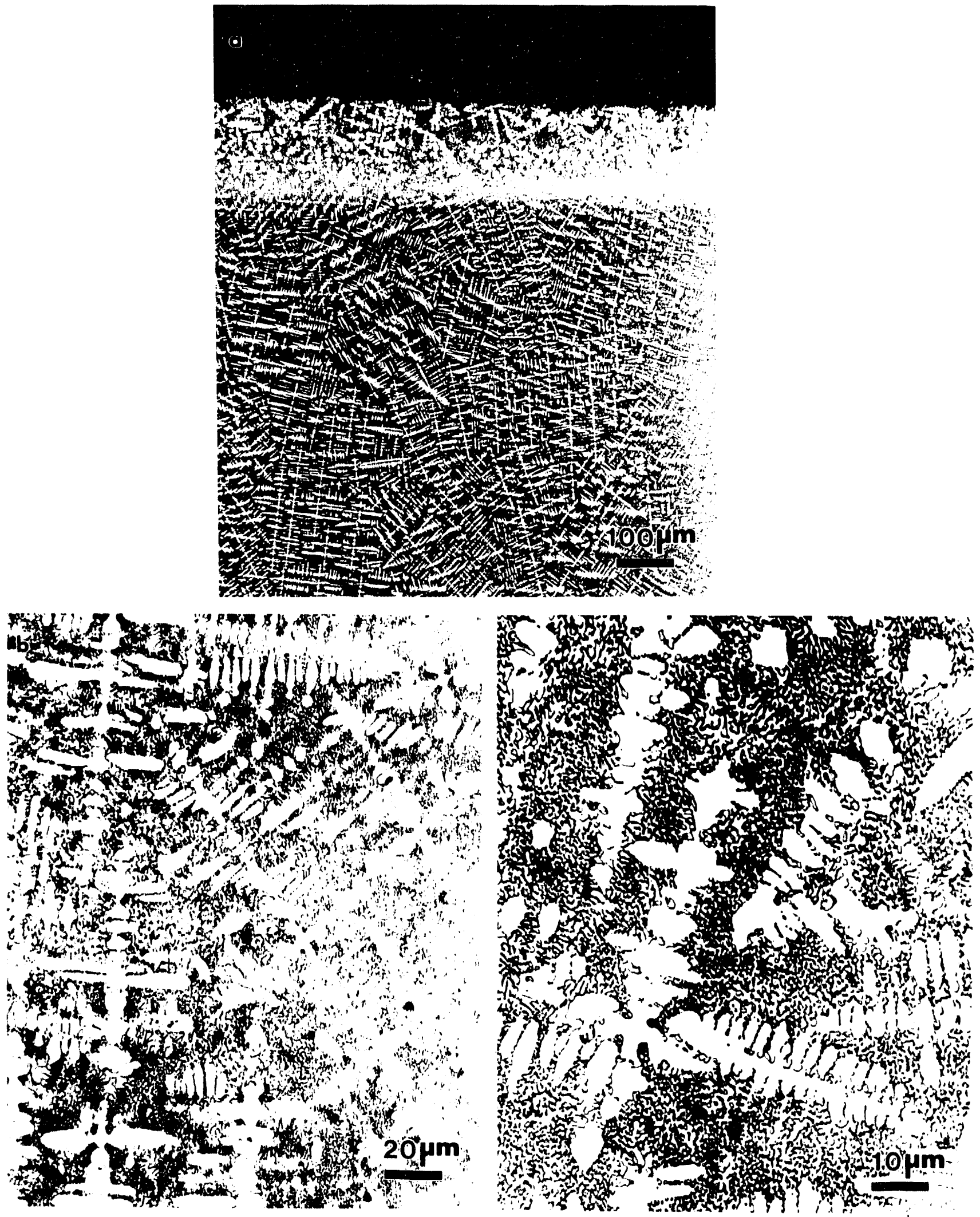

Figure 12. As-Weld Microstructure of the High Chromium Iron Weld Overlay Coating; (a) top of the coating; (b) dendrites in the coating microstructure; (c) dendrites (white) and interdendritic phases (dark). 


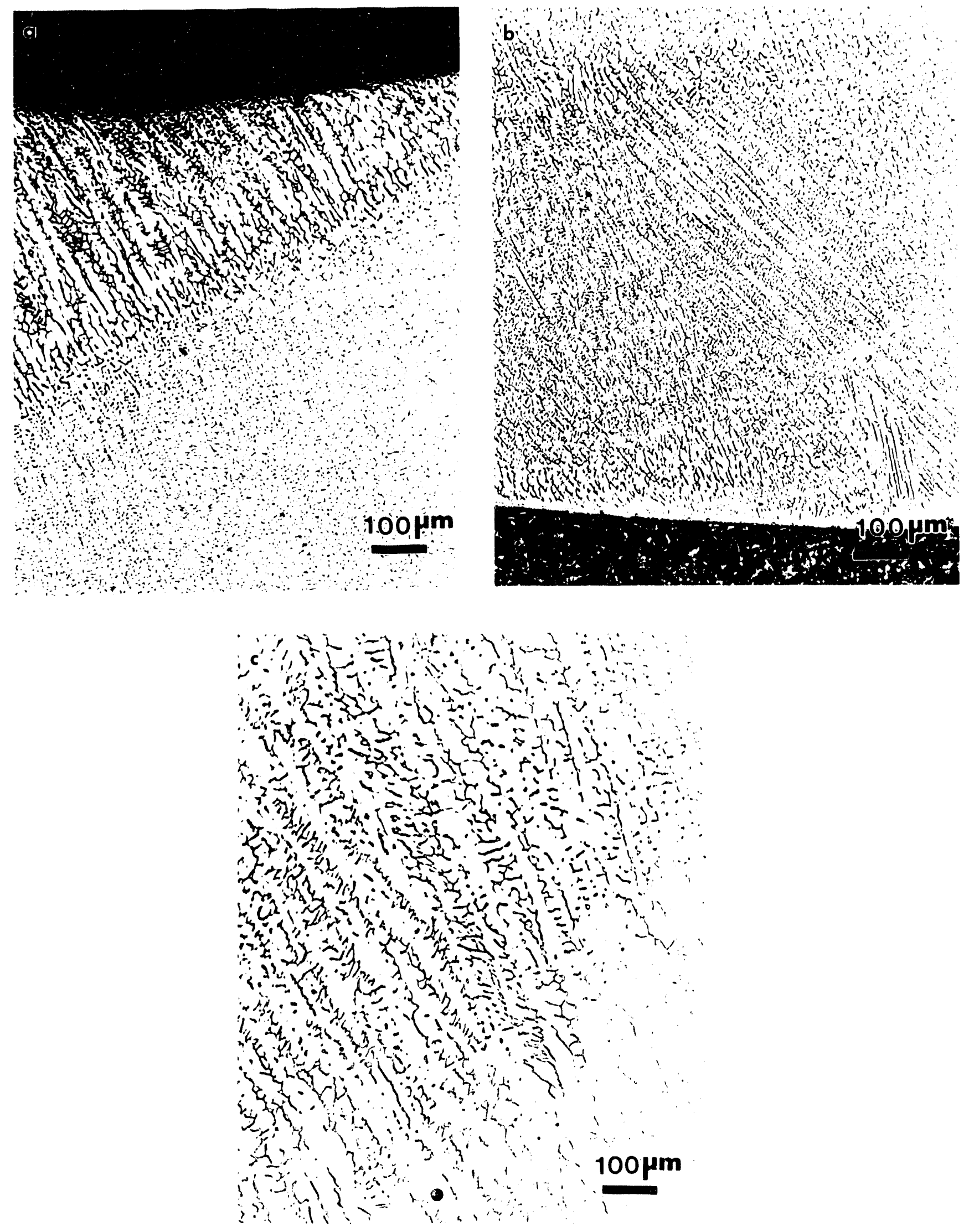

Figure 13. As-Weld Microstructure of the 316L SS Weld Overlay Coating; (a) top of the coating; (b) coating/substrate interface; (c) delta ferrite in austenitic matrix. 

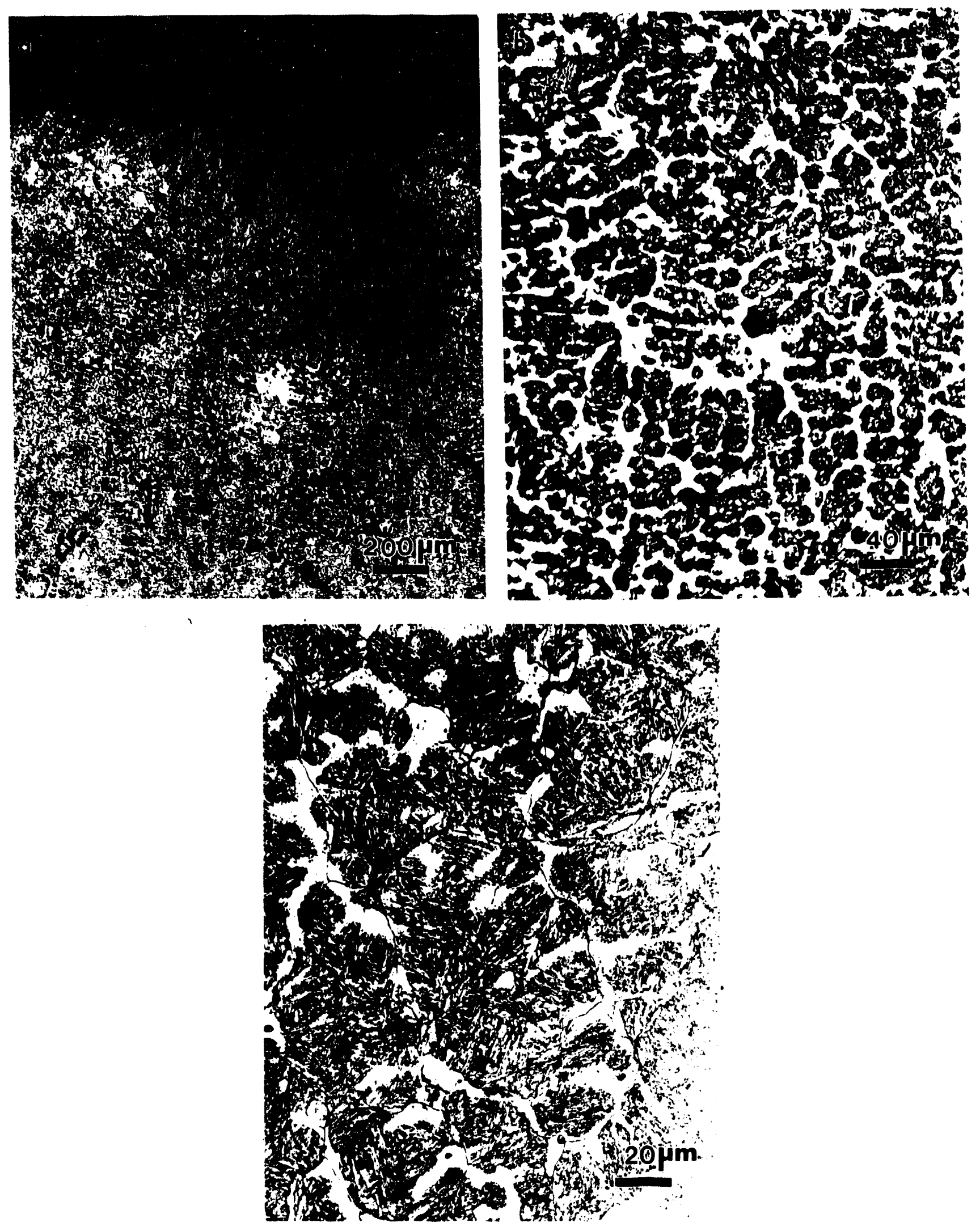

Figure 14. As-Weld Microstructure of the 420 SS Weld Overlay Coating; (a) top of the coating; (b) dendrites of the lath martensite; (c) lath martensite within prior austenite grains. 


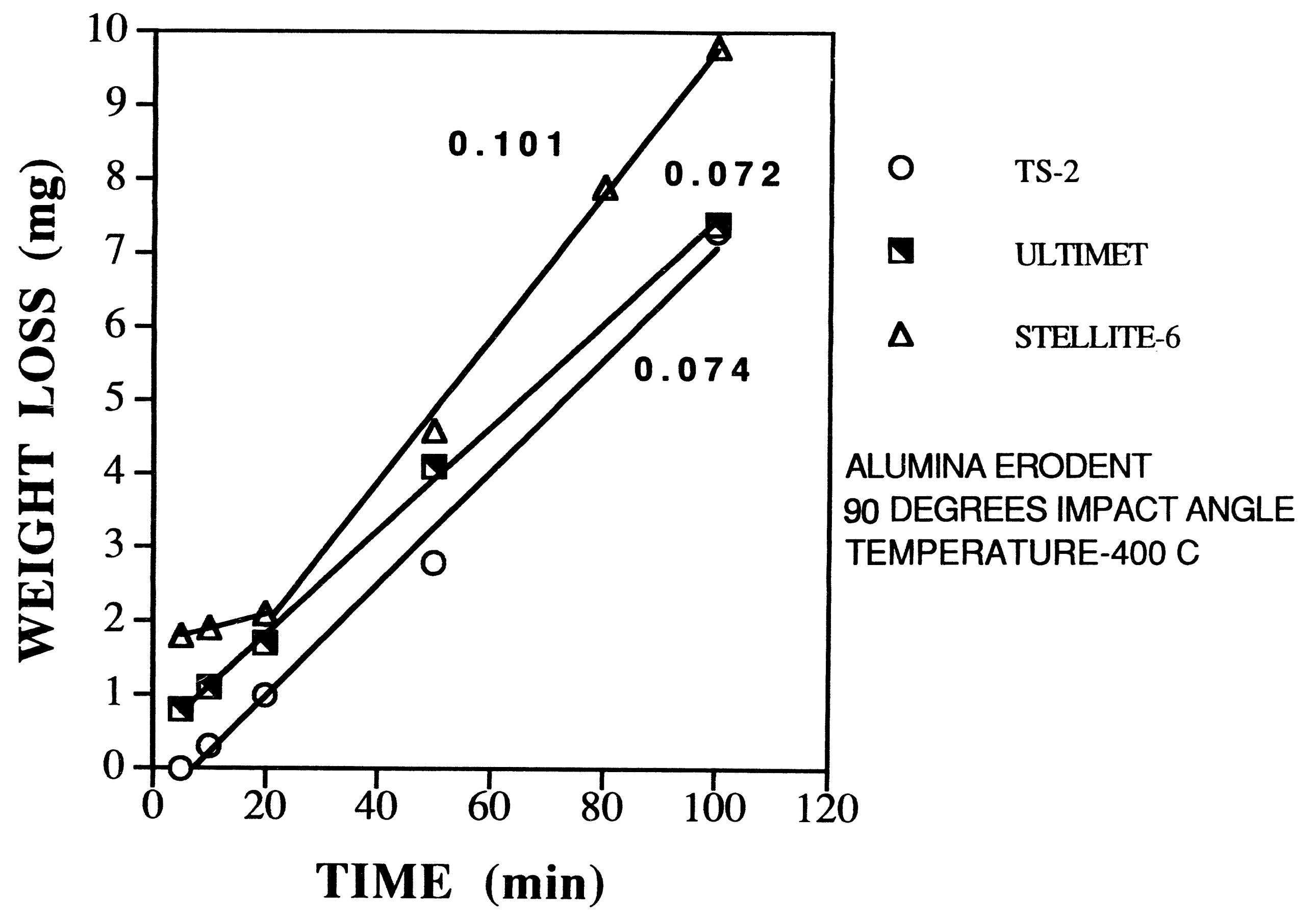

Figure 15. Weight Loss As a Function of Time For Cobalt-Base Weld Overlay Coatings $\left(90^{\circ}\right.$ 


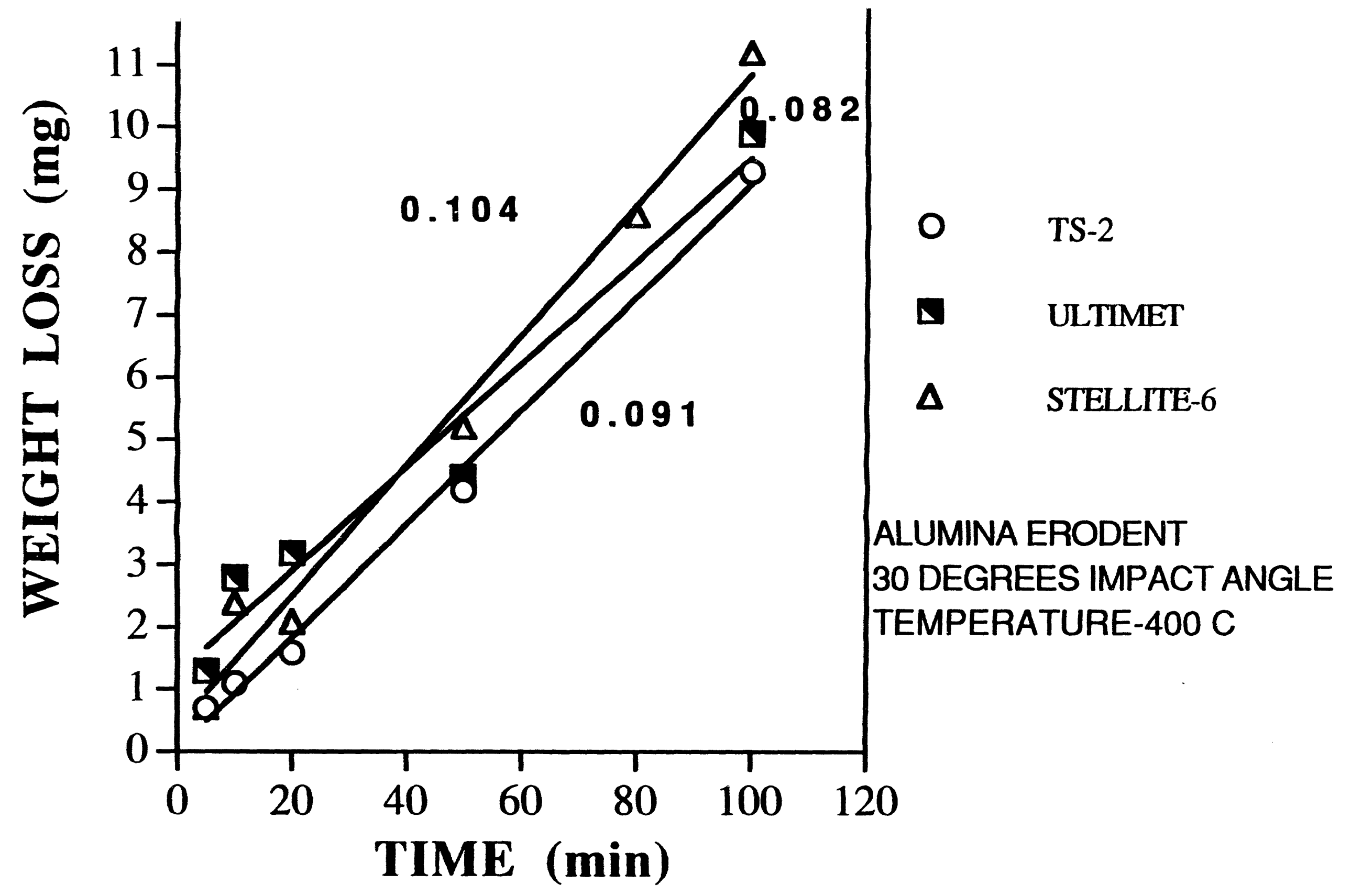

Figure 16. Weight Loss As a Function of Time For Cobalt-Base Weld Overlay Coatings (30 impact angle). 
$\exists า \fallingdotseq N \forall \perp O \forall d W I$ S $\exists \exists y 9 \exists 006$ ว 00t- $\exists y \cap \perp \forall y \exists d W \exists \perp$ $\perp N \exists 0 O 8 \exists \forall N I W \cap 7 \forall$

ZZ-XOTTHLSHH

SZ9-TINOJNI

\section{(U!U) HWIL}

OZI $00 \mathrm{I} \quad 08 \quad 09 \quad 07 \quad 0 Z \quad 0$

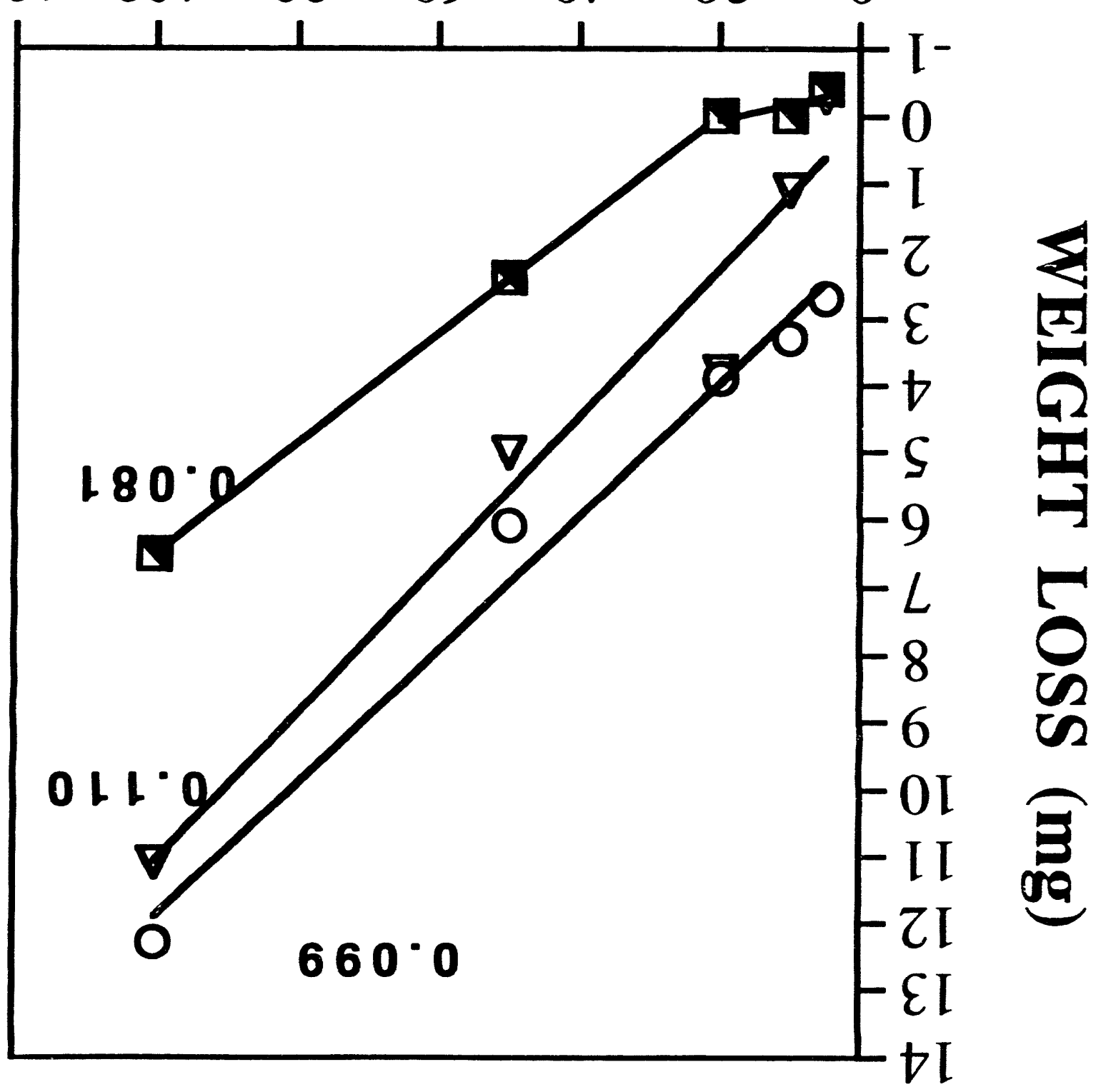




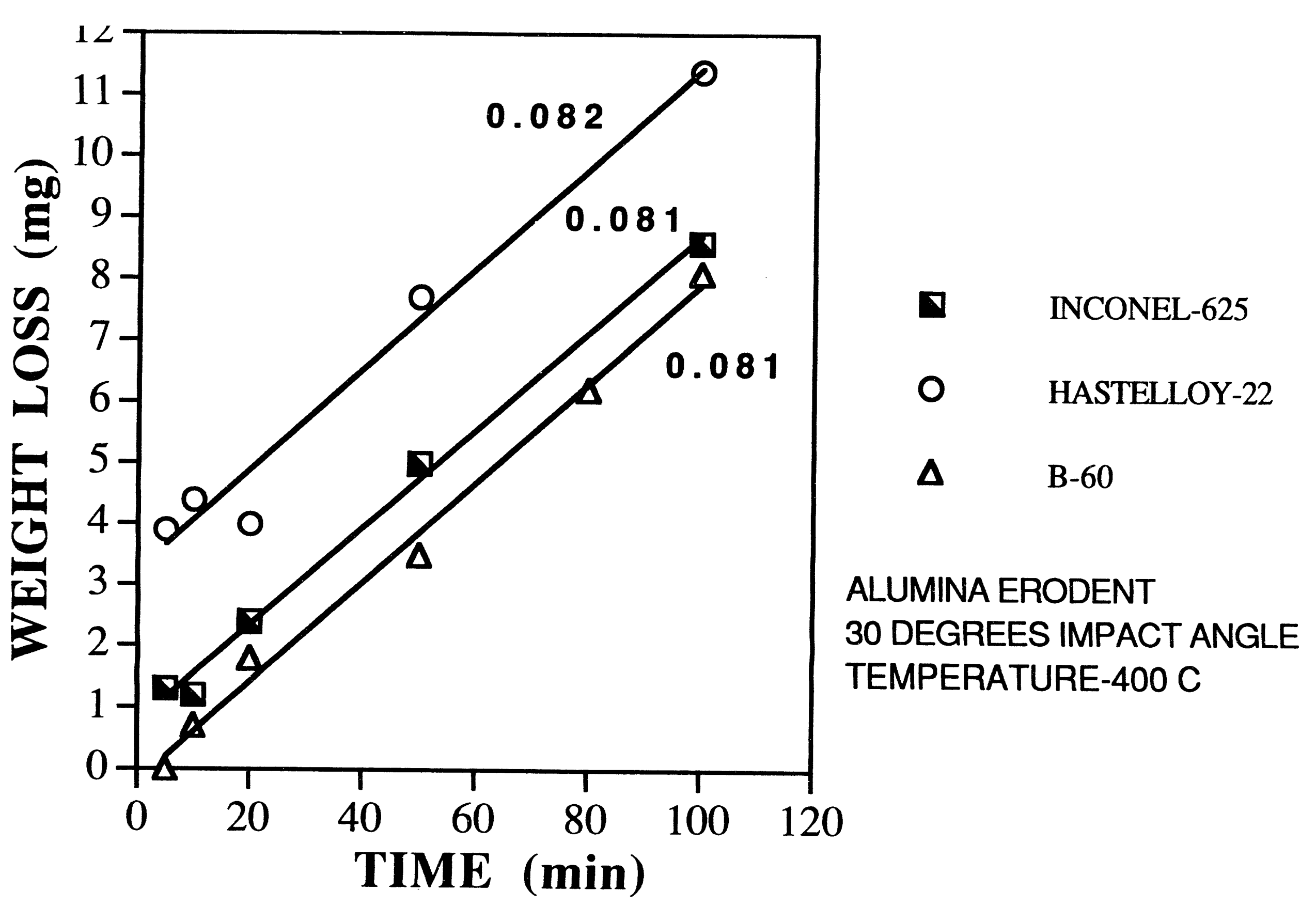

Figure 18. Weight Loss As a Function of Time For Nickel-Base Weld Overlay Coatings (30 impact angle. 


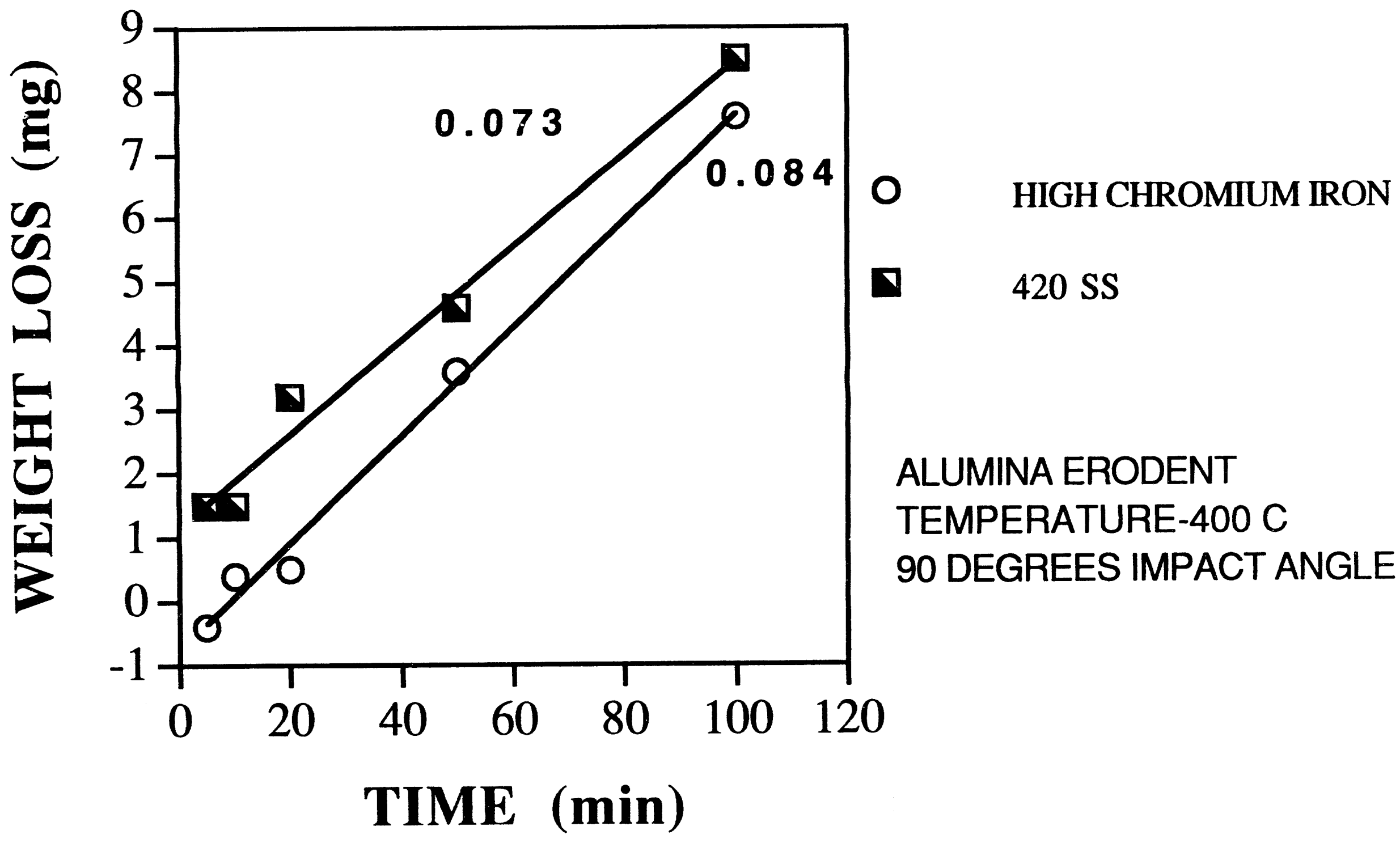

Figure 19. Weight Loss As a Function of Time For Iron-Base Weld Overlay Coatings $\left(90^{\circ}\right.$ 


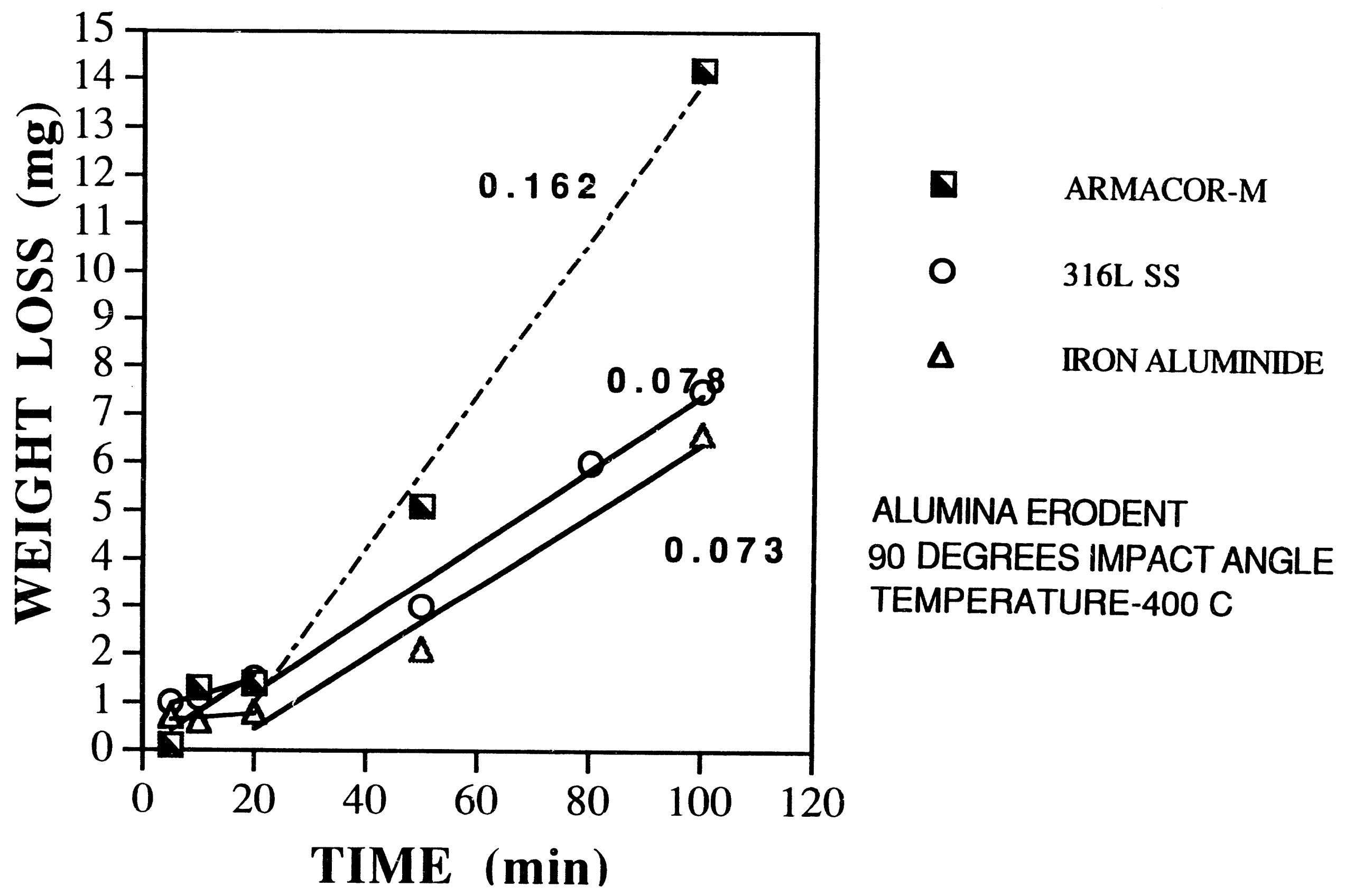

Figure 20. Weight Loss As a Function of Time For Iron-Base Weld Overlay Coatings $\left(90^{\circ}\right.$ impact angle). 


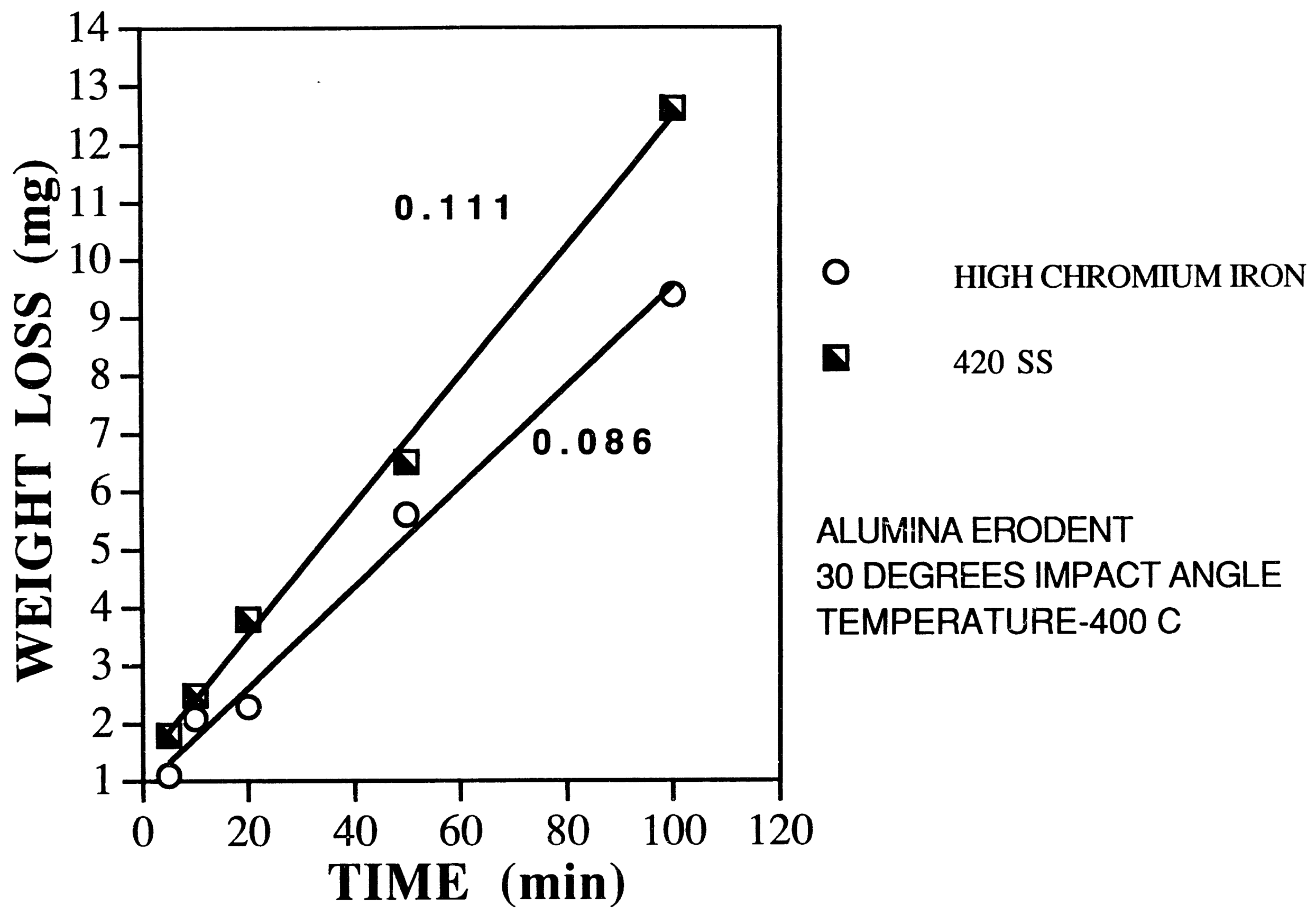

Figure 21. Weight Loss As a Function of Time For Iron-Base Weld Overlay Coatings $\left(30^{\circ}\right.$ impact angle). 


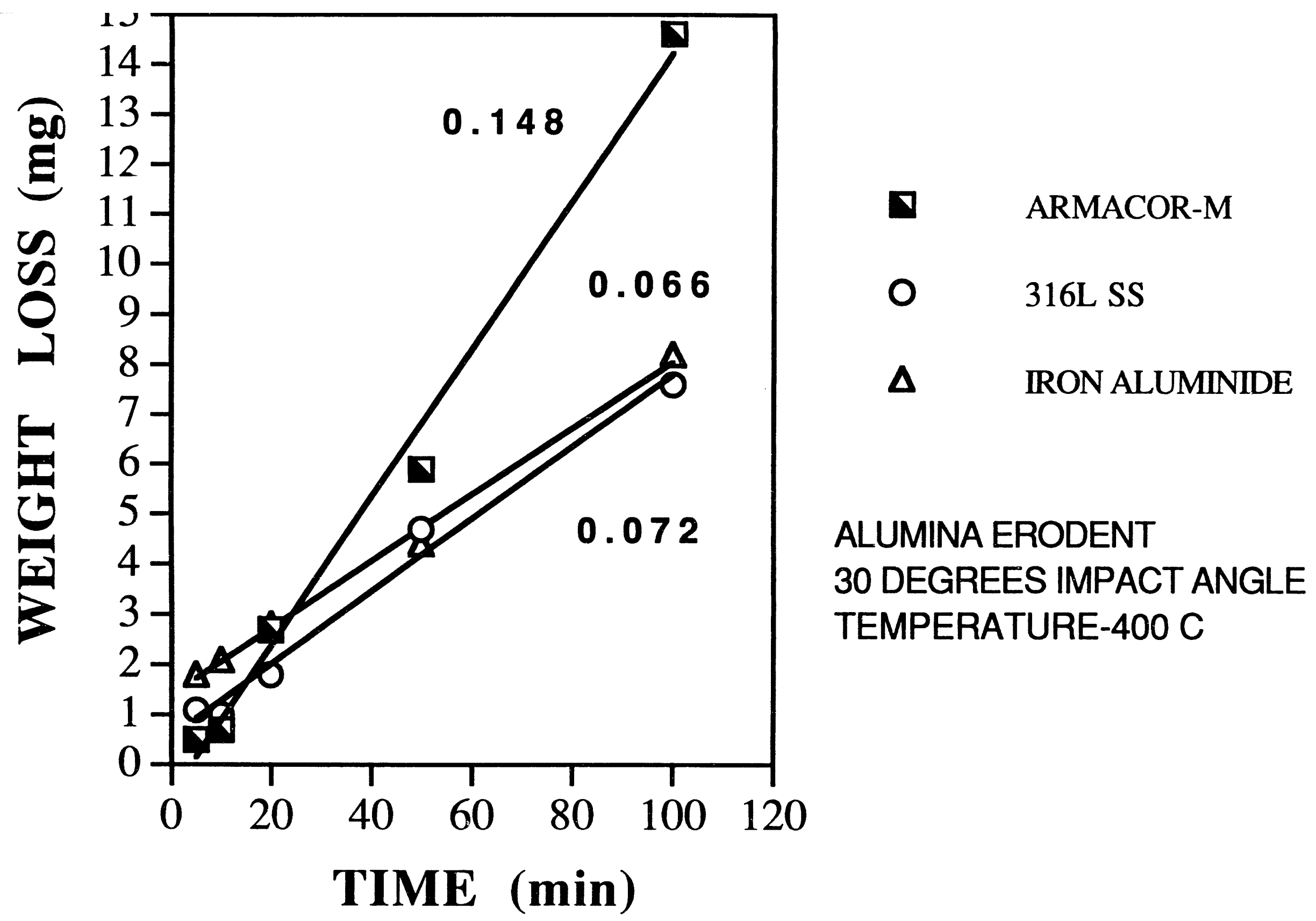

Figure 22. Weight Loss As a Function of Time For Iron-Base Weld Overlay Coatings (30 impact angle). 


\section{STELLITE-6 WELD OVERLAY COATING}

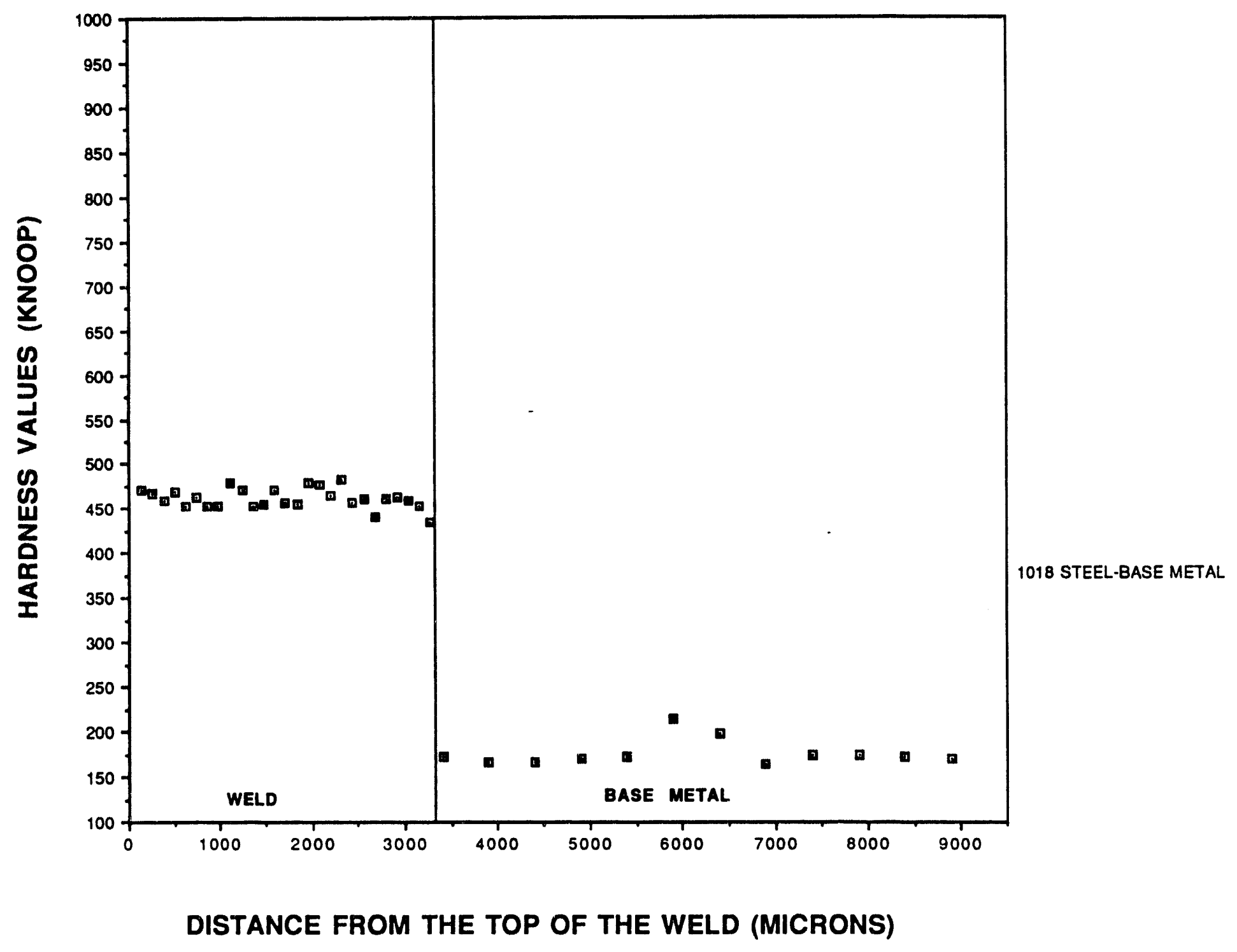

Figure 23 Microhardness Values Across the Transverse Section of the Weld. Stellite-6 Weld Overlay Coating. 
TS-2 WELD OVERLAY COATING

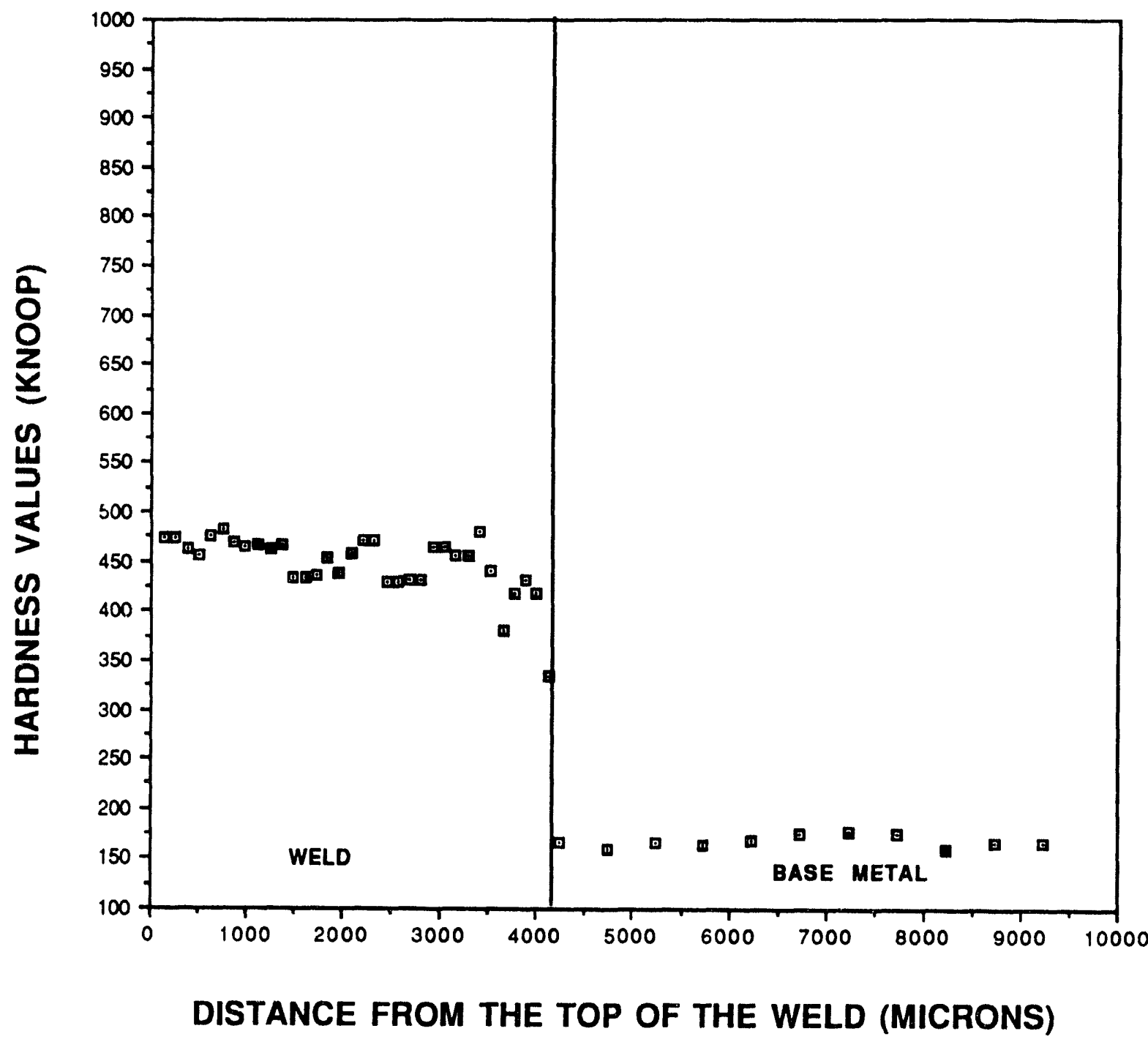

Figure 24. Microhardness Values Across the Transverse Section of the Weld. TS-2 Weld Overlay Coating. 
"ULTIMET" WELD OVERLAY COATING

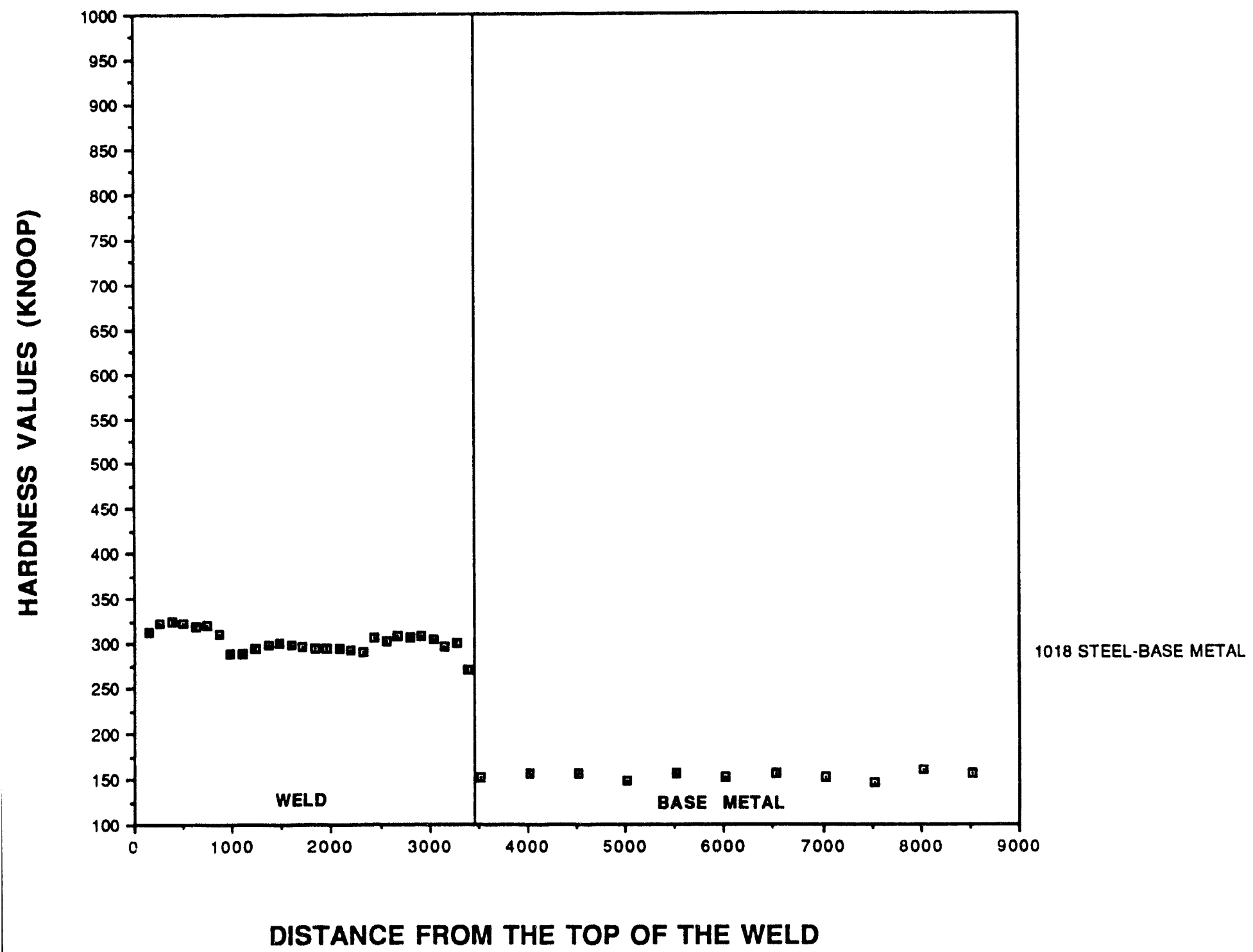

Figure 25. Microhardness Values Across the Transverse Section of the Weld. Ultimet Weld Overlay Coating. 


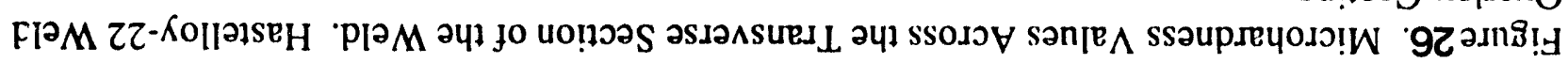

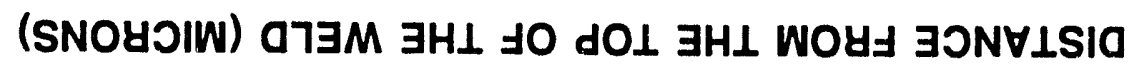

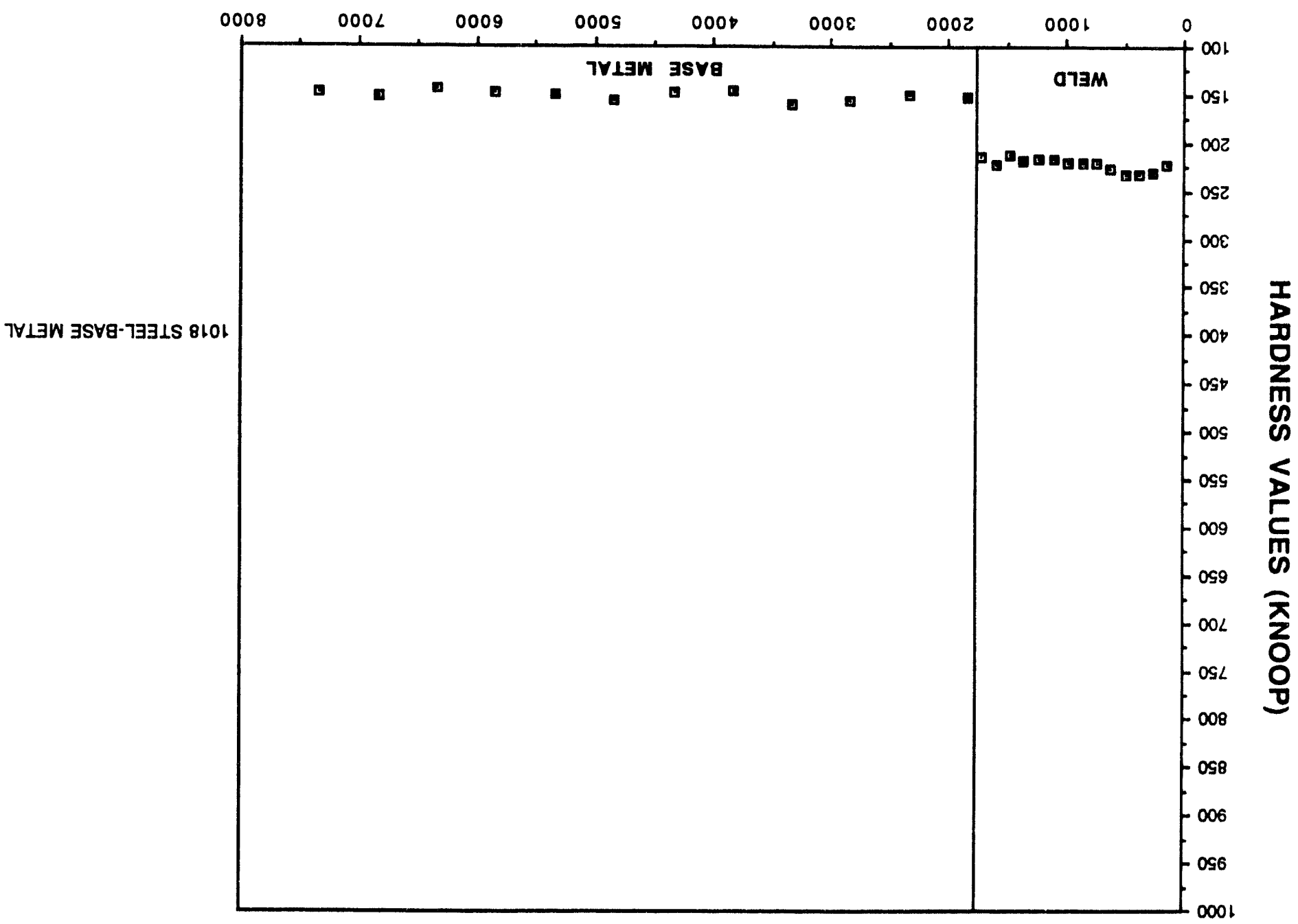




\section{INCONEL-625 WELD OVERLAY COATING}

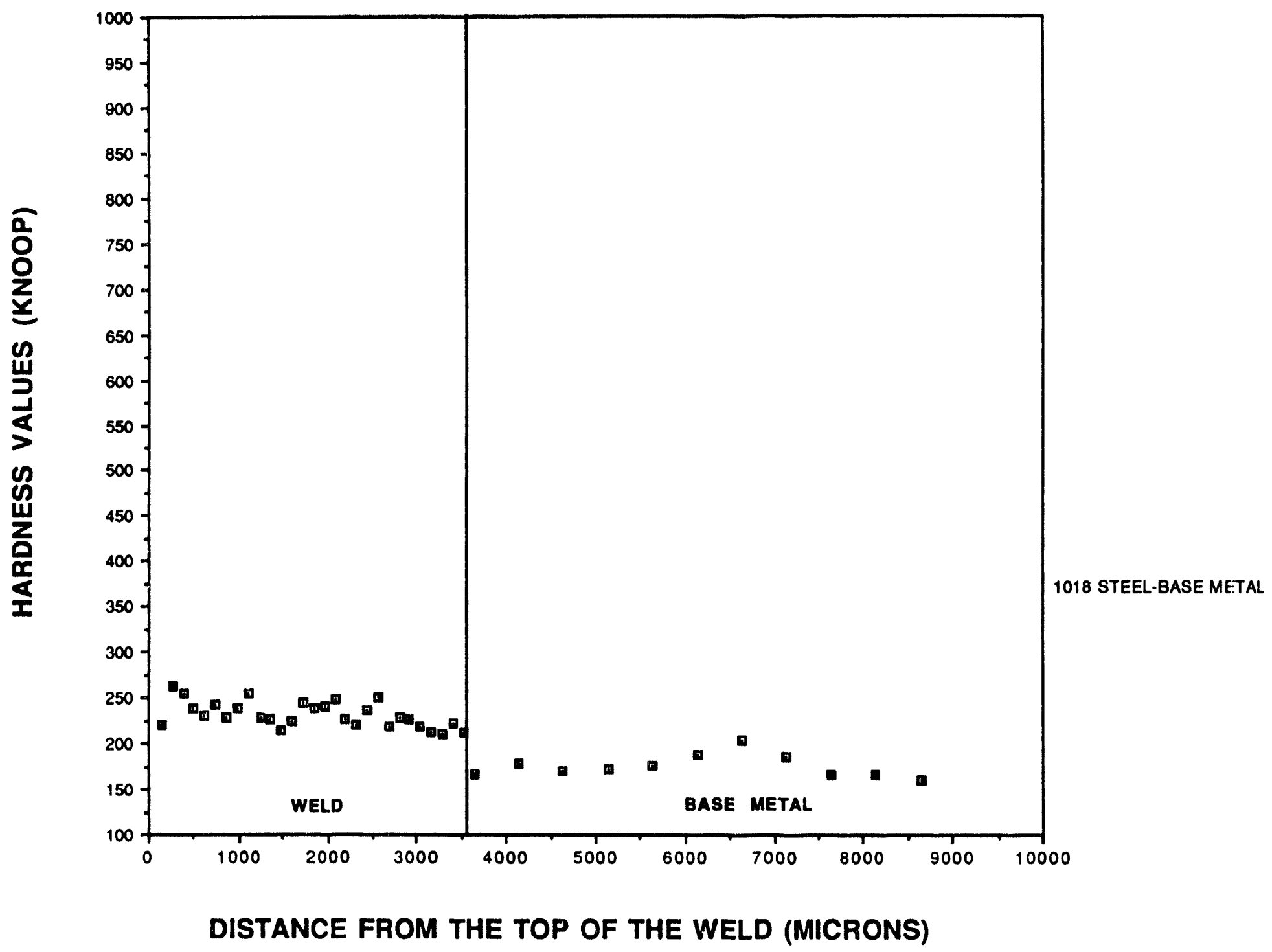

Figure 27. Microhardness Values Across the Transverse Section of the Weld. Inconel-625 Weld Overlay Coating. 


\section{B-60 WELD OVERLAY COATING}

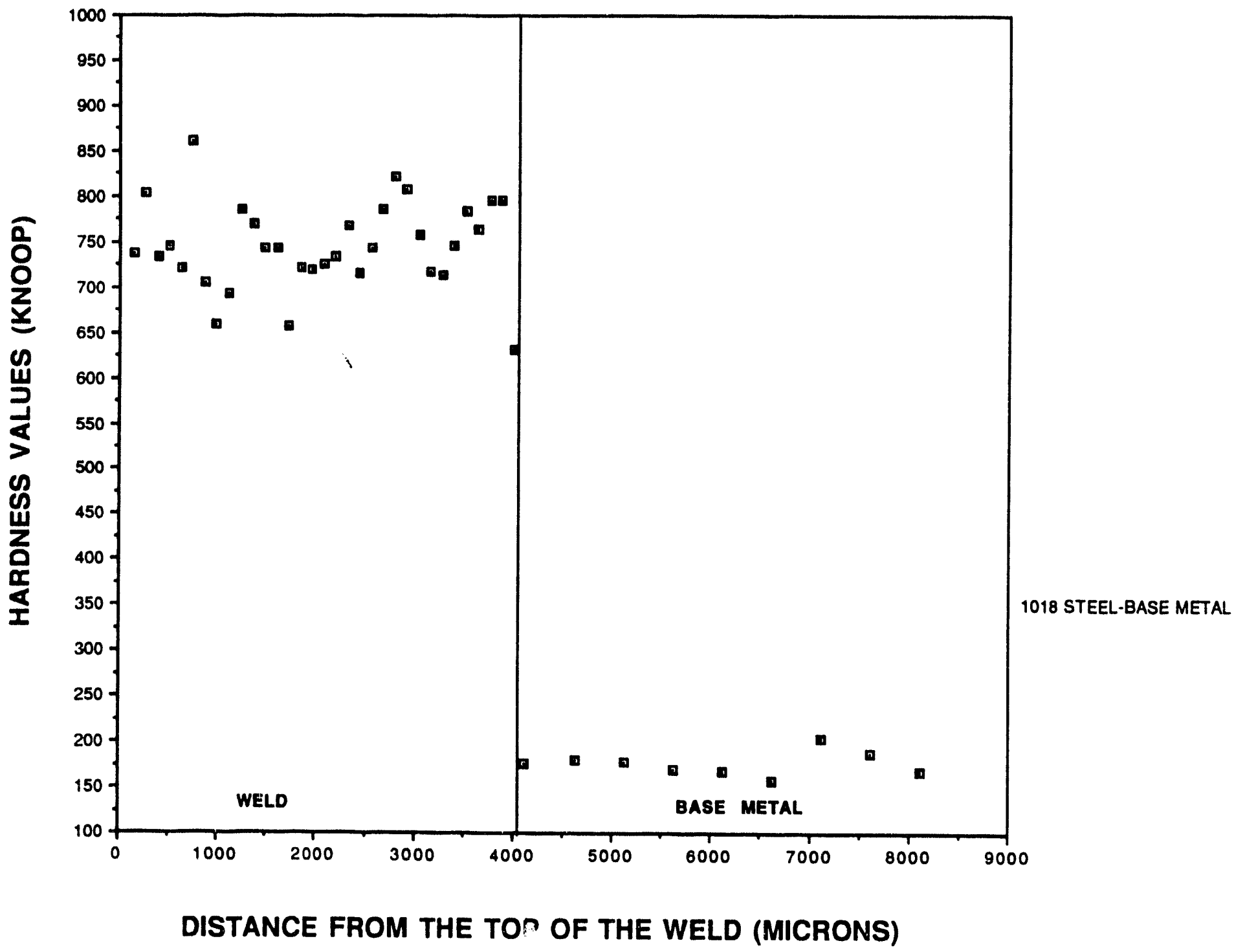

Figure 28. Microhardness Values Across the Transverse Section of the Weld. B-60 Weld Overlay Coating. 


\section{ARMACOR-M WELD OVERLAY COATING}

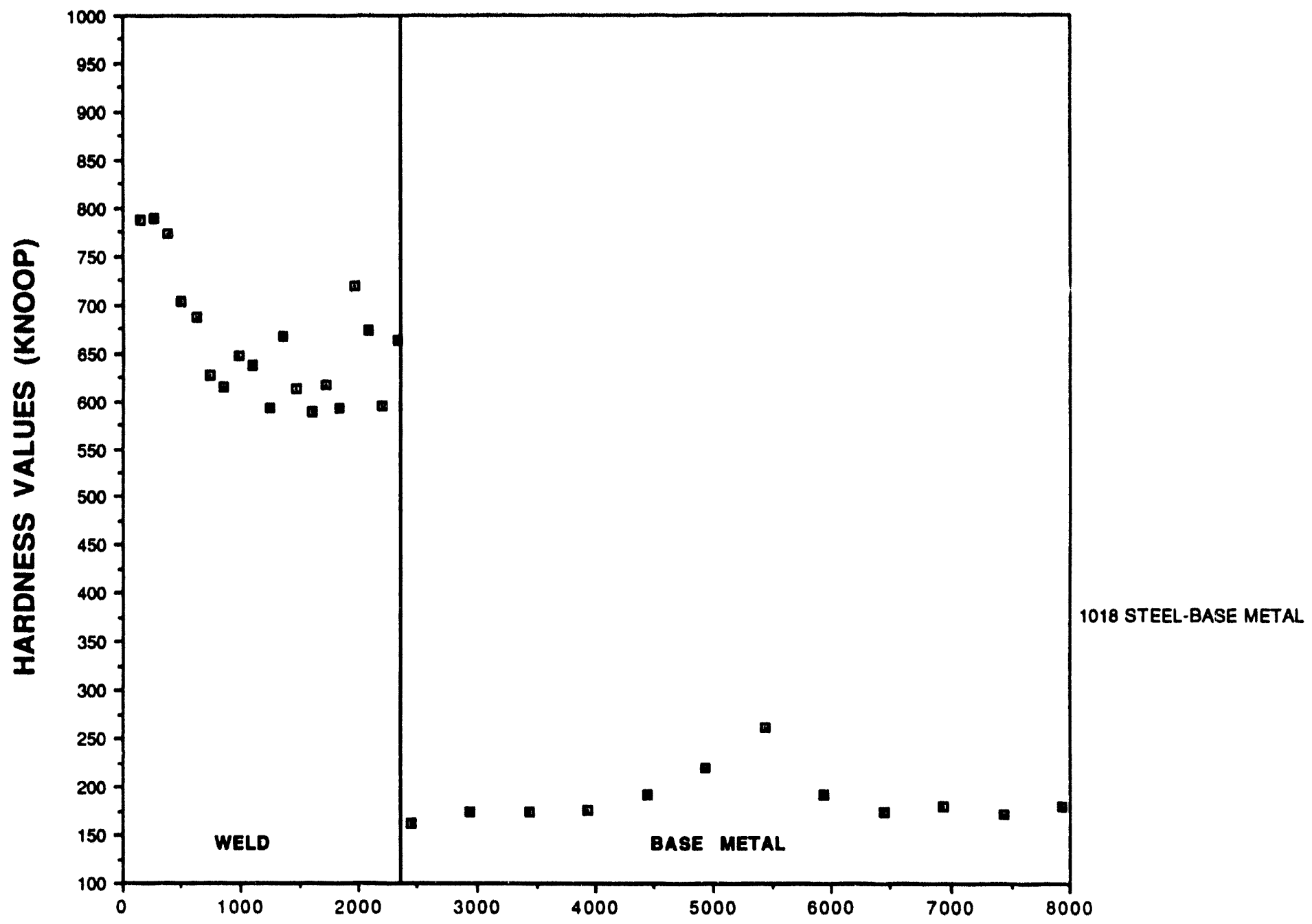

DISTANCE FROM THE TOP OF THE WELD (MICRONS)

Figure 29. Microhardness Values Across the Transverse Section of the Weld. Armacor-M Weld Overlay Coating. 
IRON-ALUMINIDE WELD OVERLAY COATING

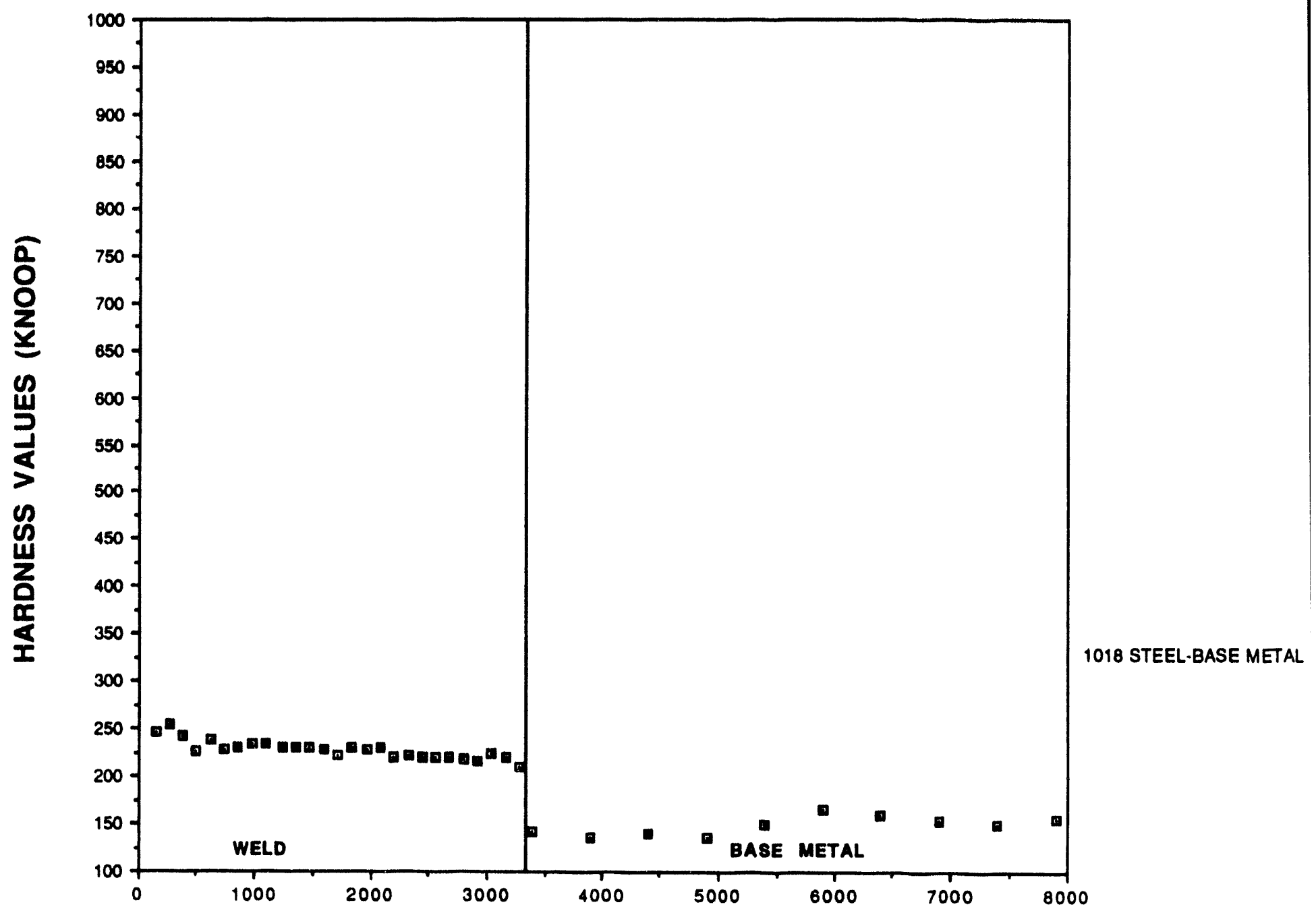

DISTANCE FROM THE TOP OF THE WELD (MICRONS)

Figure 31. Microhardness Values Across the Transverse Section of the Weld. Iron-Aluminide Weld Overlay Coating. 
HIGH CHROMIUM IRON WELD OVERLAY COATING

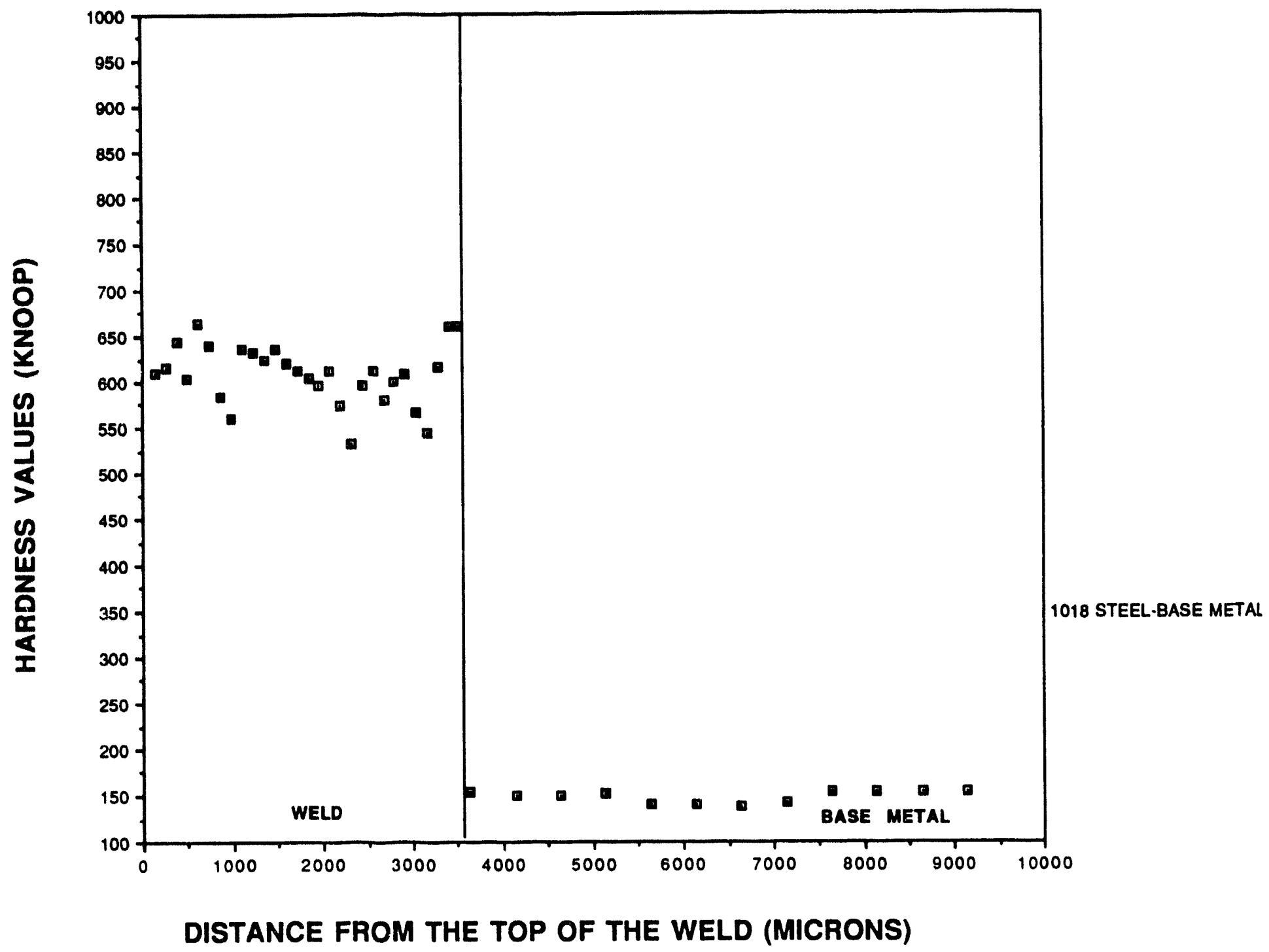

Figure 32. Microhardness Values Across the Transverse Section of the Weld. High Chromium Iron Weld Overlay Coating. 
316L SS WELD OVERLAY COATING

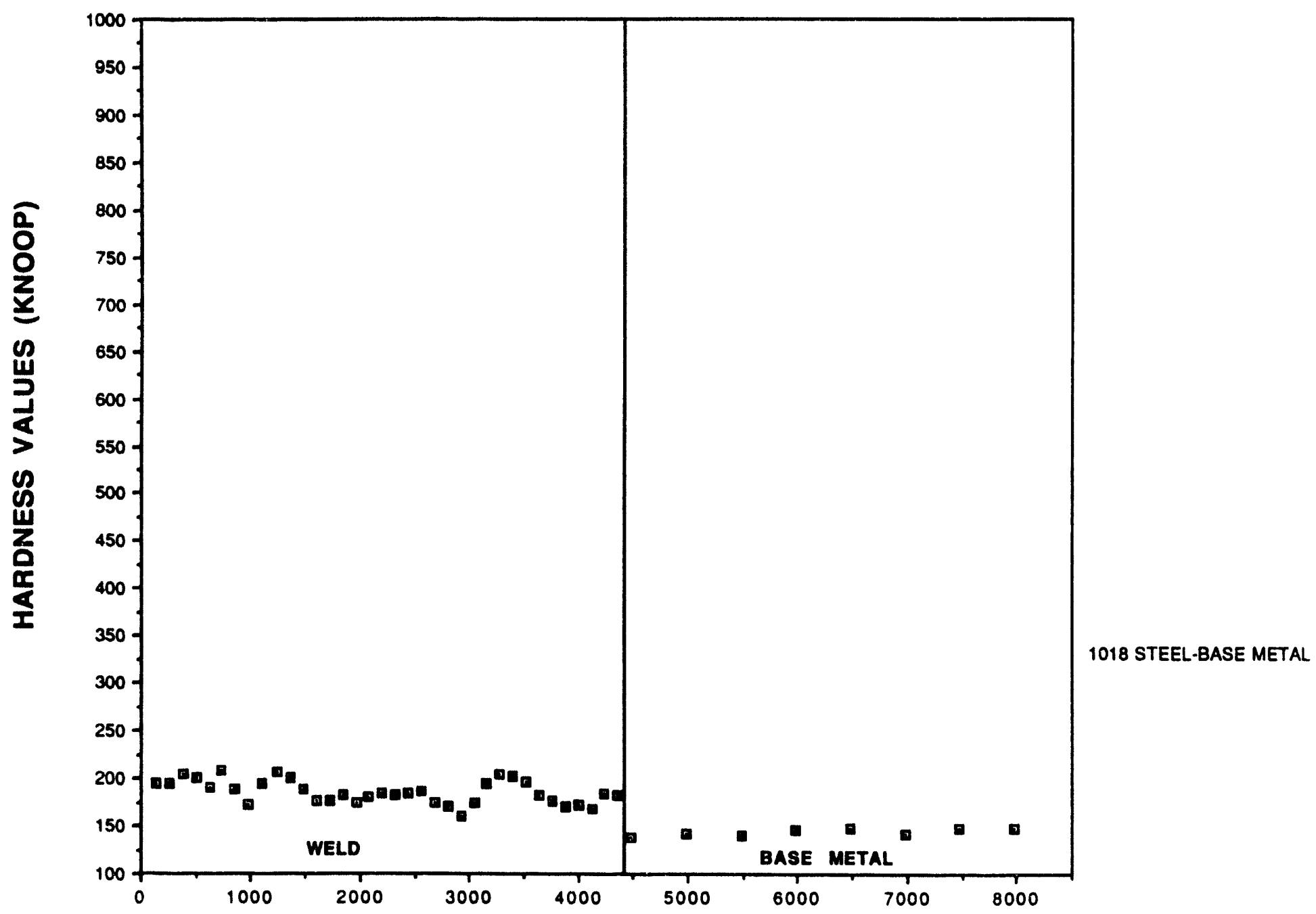

DISTANCE FROM THE TOP OF THE WELD (MICRONS)

Figure 33. Microhardness Values Across the Transverse Section of the Weld. 316L SS Weld Overlay Coating. 


\section{SS WELD OVERLAY COATING}

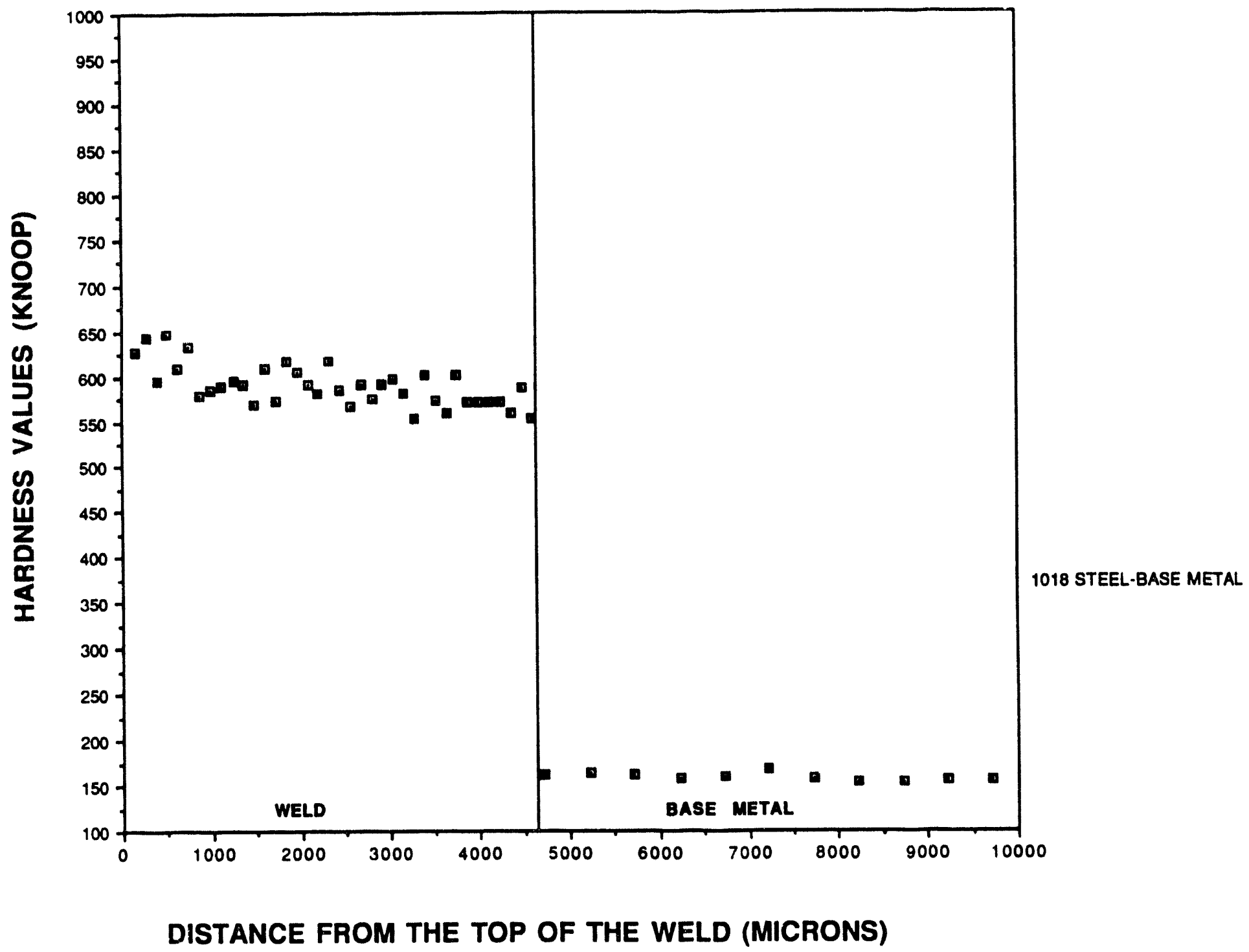

Figure 34. Microhardness Values Across the Transverse Section of the Weld. 420 SS Weld Overlay Coating. 


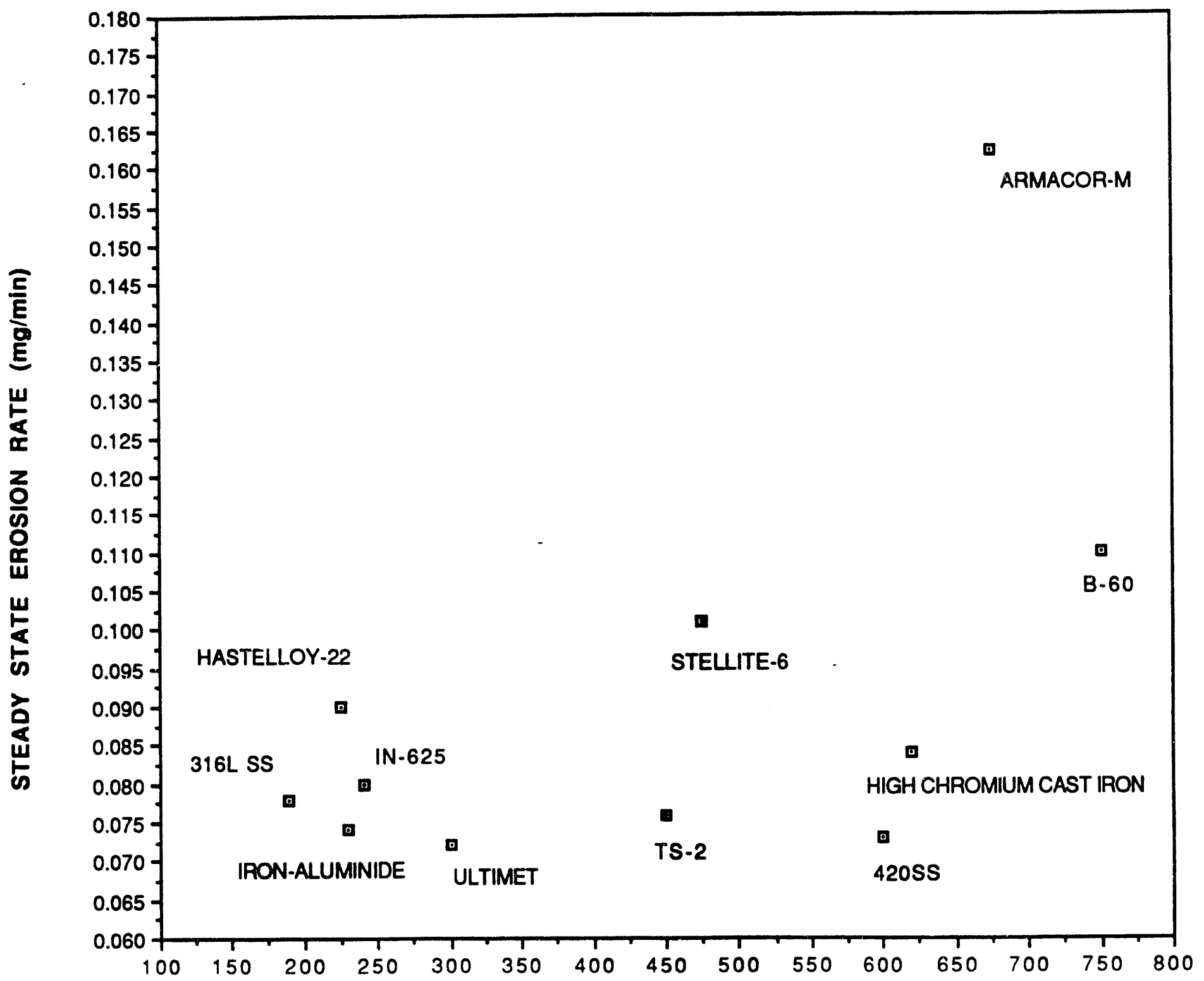

AVERAGE MICROHARDNESS VALUES (KNOOP)

Figure 35. Steady State Erosion Rate of Weld Overlay Coatings As a Function of Room Temperature Microhardness. Erosion Rates Were Determined For $90^{\circ}$ Impact Angle. 


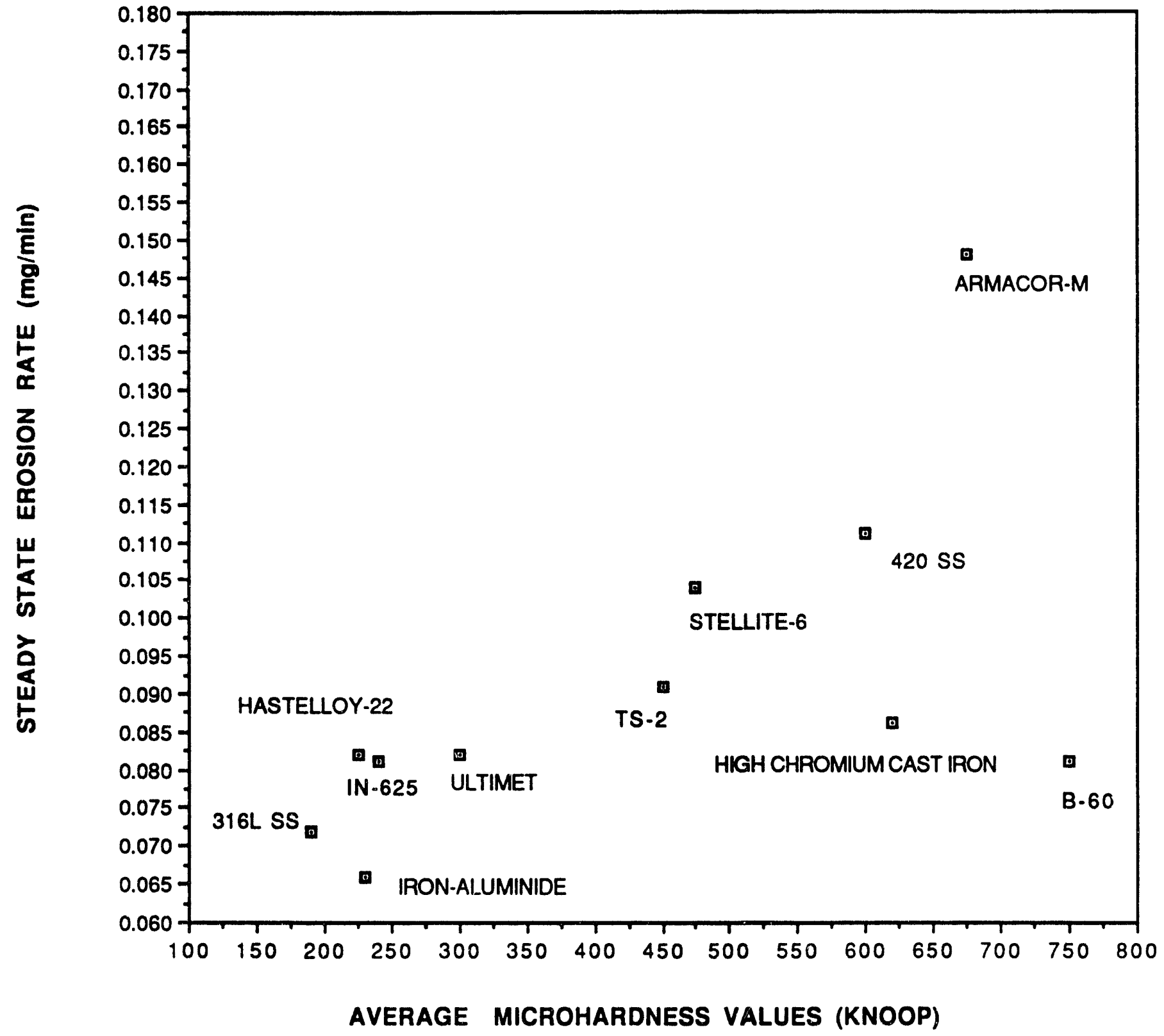

Figure 36. Steady State Erosion Rate of Weld Overlay Coatings As a Function of Room emperature Microhardness. Erosion Rates Were Determined For $30^{\circ}$ Impact Angle. 

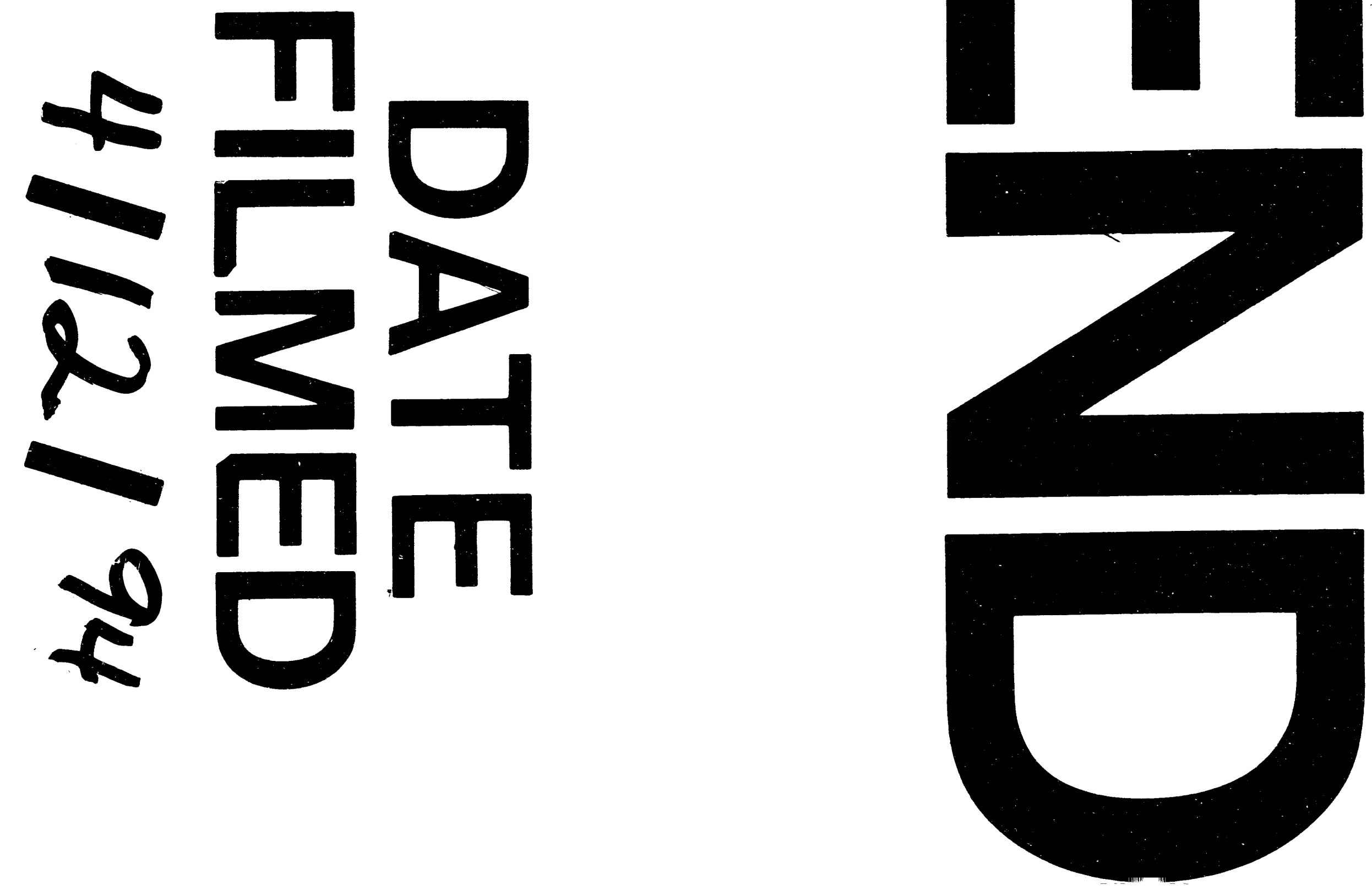


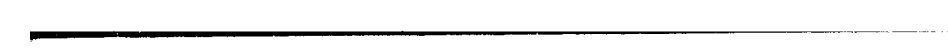
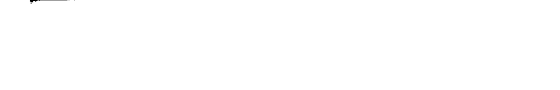